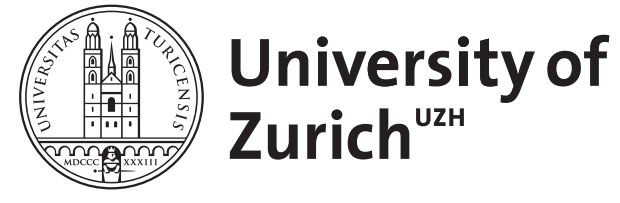

\title{
Energetics and the evolution of human brain size
}

\author{
Navarrete, A ; van Schaik, C P ; Isler, K
}

\begin{abstract}
The human brain stands out among mammals by being unusually large. The expensive-tissue hypothesis explains its evolution by proposing a trade-off between the size of the brain and that of the digestive tract, which is smaller than expected for a primate of our body size. Although this hypothesis is widely accepted, empirical support so far has been equivocal. Here we test it in a sample of 100 mammalian species, including 23 primates, by analysing brain size and organ mass data. We found that, controlling for fat-free body mass, brain size is not negatively correlated with the mass of the digestive tract or any other expensive organ, thus refuting the expensive-tissue hypothesis. Nonetheless, consistent with the existence of energy trade-offs with brain size, we find that the size of brains and adipose depots are negatively correlated in mammals, indicating that encephalization and fat storage are compensatory strategies to buffer against starvation. However, these two strategies can be combined if fat storage does not unduly hamper locomotor efficiency. We propose that human encephalization was made possible by a combination of stabilization of energy inputs and a redirection of energy from locomotion, growth and reproduction.
\end{abstract}

DOI: https://doi.org/10.1038/nature10629

Posted at the Zurich Open Repository and Archive, University of Zurich

ZORA URL: https://doi.org/10.5167/uzh-57326

Journal Article

Accepted Version

Originally published at:

Navarrete, A; van Schaik, C P; Isler, K (2011). Energetics and the evolution of human brain size. Nature, 480(7375):91-93.

DOI: https://doi.org/10.1038/nature10629 
1 Title: Energetics and the evolution of human brain size: no gut-brain trade-off in mammals

2 Authors: Ana Navarrete, Carel P. van Schaik, Karin Isler

3 Abstract

4 The human brain stands out among mammals by being unusually large. The Expensive Tissue

5 Hypothesis ${ }^{1}$ explains its evolution by proposing a trade-off between the size of the brain and that of

6 the digestive tract, which is smaller than expected for a primate of our body size. Although this

7 hypothesis is widely accepted, empirical support to date is equivocal. Here, we test it in a sample of

8100 mammal species, including 23 primates, with matching brain size and organ mass data. We

9 found that, controlling for fat-free body mass, brain size is not negatively correlated with the mass

10 of the digestive tract or any other expensive organ, thus refuting the Expensive Tissue Hypothesis.

11 Nonetheless, consistent with the existence of energy trade-offs with brain size we find that the size

12 of brains and adipose depots are negatively correlated in mammals, suggesting that encephalization

13 and fat storage are compensatory strategies to buffer against starvation. However, these two

14 strategies can be combined if fat storage does not unduly hamper locomotor efficiency. We propose

15 that human encephalization was made possible by a combination of stabilization of energy inputs

16 and a redirection of energy from locomotion, growth and reproduction.

19 Brains are energetically expensive ${ }^{2}$. The human brain is about three times larger than that of our 20 closest living relative, the chimpanzee, and thus requires much more energy. However, relative

21 whole-body energy consumption rates of individuals at rest are about equal in the two species ${ }^{3}$,

$1 \quad$ Navarrete et al. - Main text 
22 which raises the question of how humans manage to cover the energetic requirements of their much

23 enlarged brains. One of the best-known attempts to solve this central riddle of human evolution is

24 the Expensive Tissue Hypothesis, proposed by Aiello and Wheeler in $1995^{1}$. It postulates an

25 evolutionary trade-off (though obviously not an immediate physiological one) between the size of

26 the brain and that of the digestive tract in anthropoid primates. Thus, if other processes have

27 reduced a species' energetic needs of digestion, it should be able to evolve a relatively larger brain.

28 It has therefore been suggested that early hominins evolved larger brains as a diet shift towards

29 more meat ${ }^{1}$, cooked food and underground tubers ${ }^{4}$ gradually allowed for a smaller digestive tract.

30 The proposed trade-off would gain much plausibility as a general principle if it would be

31 confirmed in other mammals. As stressed by Aiello et al. ${ }^{5}$, empirical support for a negative

32 correlation across anthropoid primate species was weak from the beginning (see Suppl. Info. section

331 for a re-analysis), and subsequent comparative studies in other taxa remained ambiguous, with

34 positive support in fish ${ }^{6}$, but not in bats or birds ${ }^{7,8}$. Yet, this highly intuitive idea has found broad

35 acceptance in palaeoanthropology 9 and many other fields ${ }^{10-12}$, and is fuelling public discussions

36 about the optimal human diet. Thus, a proper empirical test of the Expensive Tissue Hypothesis

37 across a broad array of taxa was urgently needed, but has so far not been conducted due to lack of

38 morphological data, nor has there been an examination of the broader trade-offs amongst other

39 expensive organs predicted by an extension of this hypothesis ${ }^{7}$.

40 Here, we examine the presence of correlated evolution of organ sizes in a new dataset of the

41 mass of various visceral organs (heart, lungs, stomach, intestines, kidneys, spleen and liver) and

42 associated brain size for 100 mammal species, including 23 primate species (see Suppl. Data).

43 Dissections followed a strict protocol and were all conducted by one of the authors (A.N.). We

$2 \quad$ Navarrete et al. - Main text 
44 excluded individuals that were immature, emaciated, pregnant, or exhibited visible organ 45 pathologies from analysis.

In this analysis, it is crucial to control for body size. The usual measure taken for this, body

47 mass, is highly affected by variation in the size of adipose depots, which may confound or even

48 reverse the direction of correlations among organs (Suppl. Fig. 2, Suppl. Table 4b). Here, we

49 therefore used fat-free body mass as the best proxy for body size. All analyses took phylogenetic

50 relatedness into account (Suppl. Fig. 3). The sample size of 100 species yields a power of 0.8 for

51 these analyses, which was determined a priori using a published dataset of 39 mammal species (see

52 Methods).

53 Contrary to the predictions of the Expensive Tissue Hypothesis, we found no negative 54 correlations between the relative size of the brain and the digestive tract, other expensive organs or 55 their combined sum among mammals or within non-human primates, controlling for fat-free body 56 mass, even though statistical power was sufficient to detect these negative correlations if they

57 existed (see Table 1). We also did not find any trade-offs amongst other expensive organs (Fig. 1).

58 These results therefore refute the Expensive Tissue Hypothesis as a general principle to explain the 59 interspecific variation of relative brain size in mammals. In our view, this finding reduces the 60 plausibility of the argument that human encephalization was made possible by a reduction of the 61 digestive $\operatorname{tract}^{1,5}$.

62 Energy trade-offs with other tissues that are less expensive but very abundant ${ }^{7}$, may 63 nonetheless explain part of brain size variation. For instance, adipose depots make up an appreciable 64 proportion of body mass in some mammals ${ }^{13}$. Although not metabolically expensive, adipose tissue 65 has an energetic cost because it has to be carried around and may increase predation-induced 66 mortality (see Suppl. Info. 3.7.). Fat stores enable animals to cope with periods of reduced food 3 Navarrete et al. - Main text 
67 intake and thus act as a physiological buffer against starvation. On the other hand, relatively large 68 brains have also been proposed to act as cognitive buffers against starvation ${ }^{14,15}$. It is therefore 69 possible that encephalization and fat storage are complementary strategies to buffer against 70 starvation. In our mammal sample, there is indeed a negative correlation between brain size and the 71 size of fat stores, controlling for fat-free body mass (Table 2 and Suppl. Info. 3.1.), with the 72 exception of primates (but see Suppl. Info. 3.6.). This negative relationship becomes stronger if 73 potential error variation is removed, for instance by analysing only wild-caught females (Fig. 2 and 74 Suppl. Info. 3.4.). The strongest trade-off between fat storage and brain size evolution is expected in 75 taxa that exhibit high cost of transport for increased whole body mass, such as climbing or flying 76 mammals and birds. The only animals that can easily combine both strategies of fat storage and 77 brain enlargement may be those that do not face increased cost of transport for increased whole 78 body mass, e.g. aquatic mammals or large bipeds ${ }^{16}$. However, more detailed studies of seasonal 79 variation in body mass are needed to investigate which conditions or lifestyles favour one or the 80 other, or a combination of both strategies.

Where does refuting the Expensive Tissue Hypothesis leave us with respect to explaining the evolution of the much enlarged human brain? Although there are various cognitive benefits to 83 increased brain size ${ }^{17}$, empirical evidence shows that a focus on the energy costs of growing and 84 maintaining brain tissue helps to explain the interspecific variation in brain size ${ }^{18}$. This approach has 85 recently been synthesized in a general energy-based framework ${ }^{19}$, which incorporates earlier ideas 86 on energetic aspects of brain size evolution ${ }^{1,5,18}$. Figure 3 depicts the two possible pathways enabling 87 increased encephalization from a given ancestral state: additional or stabilized energy inputs, and 88 redirection of energy from other functions. Here we apply this framework to develop hypotheses for 89 the remarkable increase of brain size during the evolution of the genus Homo.

$4 \quad$ Navarrete et al. - Main text


Larger brains are sometimes paid for by a permanent increase in net energy intake of an

91 organism, as indexed by its basal metabolic rate (BMR), as shown by the positive correlation

92 between BMR and brain size in a large sample of placental ${ }^{20}$ and marsupial mammals ${ }^{21}$. This was

93 confirmed in the present data set, where we could control for fat-free body mass (N=64, PGLS,

94 brain size as response, fat-free body mass and body mass associated with BMR measurements as

95 covariates, effect of BMR: lambda=0.96, $\mathrm{p}=0.026$, beta=0.24). We humans exhibit the BMR

96 expected for a mammal or primate of our body mass, but because we have much larger adipose

97 depots (about $14-26 \%$ in healthy adults ${ }^{22}$ ) than chimpanzees and bonobos (about $3-10 \%{ }^{23}$ ), human

98 BMR relative to fat-free body mass is appreciably higher than theirs ${ }^{24}$. Therefore, if extant apes are

99 representative of the last common ancestor, brain enlargement during human evolution was partially

100 paid for through a permanent increase in net energy intake.

Starting with Early Pleistocene Homo, this increase could have come from any of the three sources listed in Figure 3. First, they improved diet quality as indicated by increased consumption of meat and bone marrow ${ }^{1}$ and by tool-assisted food processing, at one point including cooking ${ }^{4}$.

104 Second, despite having moved into highly seasonal habitats ${ }^{9}$ they reduced temporal fluctuations in 105 energy budgets by cognitive buffering ${ }^{25}$, which is also known for other primates ${ }^{15}$ and birds ${ }^{14}$. Third, 106 provisioning and food sharing probably arose with the adoption of cooperative breeding and 107 substantial meat acquisition among the earlier representatives of the genus Homo $^{4,26}$. Comparative 108 research suggests that such energy subsidies for reproducing females and dependent offspring can 109 support increased brain size $\mathrm{e}^{19,21}$.

The second pathway to brain enlargement is increased energy allocation to the brain by 111 savings on other expensive functions, although the Expensive Tissue Hypothesis for organs is no 112 longer supported. One likely trade-off could be found between brain size and the costs of $5 \quad$ Navarrete et al. - Main text 
113 locomotion. The efficient form of bipedal locomotion that arose with the transition from 114 australopithecines to early Homo $^{27}$ could have lead to major reductions in energy expenditure in two 115 ways. On one hand, its low costs in comparison with the climbing and quadrupedal locomotion of 116 nonhuman apes ${ }^{28}$ should have lowered daily energy expenditure on locomotion ${ }^{7}$, and on the other 117 hand, bipedalism may reduce the effect of increased weight due to adipose depots on the energy 118 costs of locomotion (Suppl. Info. 3.7). A second potential trade-off would be the one between brain 119 size and production, comprising both growth and reproductive effort, which has been demonstrated

120 for mammals ${ }^{19,29}$. Beginning with early Homo our lineage has increased brain size and reduced the 121 pace of life history ${ }^{30}$, but nonetheless increased birth rates due to cooperative breeding.

122 In sum, we do not claim unique processes operating exclusively in human evolution. All 123 these processes are known to operate among mammals in general. We propose that during human 124 evolution improved diet quality, allomaternal subsidies, cognitive buffering, reduced locomotion 125 costs and reduced allocation to production all operated simultaneously, thus enabling the 126 extraordinary brain enlargement in our lineage. 
Power analysis: To estimate the sample size needed to detect a correlation between brain size and

130 digestive tract mass in mammals controlling for fat-free body mass, we used an independent dataset

131 of 39 mammal species ${ }^{31}$. In a multiple regression, digestive tract mass has a standard error of the

132 residual error sigma of 0.343 , and a raw effect size delta of 0.096 . Therefore, for a level of

133 significance of alpha $=0.05$, the sample size required to achieve a power of 0.8 is 103 species. We

134 thus aimed at collecting data from more than 100 mammal species.

135 Specimens: 454 specimens of 133 mammal species were obtained from various sources and 136 dissected following a strict protocol (Suppl. Info. 2.) by one author (A.N.). Visceral organs (kidneys, 137 spleen, liver, stomach, intestines, heart and lungs) were separated, cleaned, emptied, and 138 immediately weighed. As skulls had to be preserved intact, cranial capacity was determined using 139 the seed filling method ${ }^{32}$, and converted into an estimate of brain mass by multiplying it with $1401.036^{33}$. Specimens were excluded from analyses if they were juvenile or subadult, emaciated, 141 pregnant, previously stored in formalin or alcohol, had visible pathologies of the organs (such as 142 tumors or internal parasites), a broken neurocranium, unknown body mass prior to dissection, or if 143 the organ measurements were incomplete. Our final sample included 191 specimens from 100 144 species, with a bias towards larger orders and especially carnivores and primates (see Suppl. Info. 145 3.2. for species and family coverage and an additional analysis on subfamily level). Species values 146 were obtained by calculating the average of male and female specimens (see Suppl. Info. 3.4. for an 147 analysis of sex-specific and wild/captive subsamples). Intestine mass was defined as the sum of 148 ileum, caecum and colon mass, and digestive tract mass as the sum of stomach and intestines mass. 149 Basal metabolic rate (BMR) data of the species of our sample or of closely related taxa were taken 150 from the literature. Data and sources are listed in Suppl. Data.

7 Navarrete et al. - Main text


Adipose depots: For 45 species in our sample, adipose depots of the whole body were measured

152 directly. For the other 55 species, only abdominal adipose depots were measured, from which we

153 calculated a proxy of total adipose depots by scaling the abdominal depots mass with a factor 3.419.

154 This scaling factor was derived from a comparison of the two measurements for 292 individuals for 155 which body mass and one of the two adipose depots measurements was available (Suppl. Fig. 1).

156 Alternatively, the total mass of adipose depots was calculated from abdominal mass using a 157 prediction equation derived from nine specimens for which both measurements were available 158 (results shown in Suppl. Info. 3.3.). Fat-free body mass was calculated as whole body mass minus 159 total adipose depots mass.

Statistical analyses: All variables were log-transformed and phylogenetic regressions were run 161 using pglmEstLambda in the $\mathrm{CAIC}^{34}$ package in $\mathrm{R}^{35}$. This function uses the phylogenetic 162 generalized least-squares (PGLS) method, estimating lambda as an index of the amount of 163 phylogenetic autocorrelation in the data. If lambda is 0 , species values are phylogenetically 164 independent and the analysis is equivalent to a species means least-squares regression. If lambda is 165 close to 1 , the phylogenetic signal implies that trait evolution follows Brownian motion, and the 166 analysis is equivalent to the classic method of calculating independent contrasts. If analyses yielded 167 unstable estimates of lambda due to the small sample size within orders (lambda not significantly 168 different from both 0 and 1), we additionally ran the analyses with lambda set to 0 or 1 . The models 169 included brain mass as response, body size as covariate and organ mass as effect.

170 Visceral organs, the brain and adipose depots are part of the same body, and therefore 171 autocorrelation effects could be suspected to influence our results. Two methods to remove these 172 effects are reported in the Suppl. Info. 3.5., and the results corroborate our findings. Analyses were \begin{tabular}{|l|l}
\hline & Navarrete et al. - Main text
\end{tabular} 
173 done both using the total sample of 100 species and the subsample with total adipose depot mass of 17445 species.

175 Whole body mass vs. fat-free body mass: Traditionally, whole body mass has been used for 176 controlling for body size effects in comparative analyses. However, this measure is highly affected 177 by variation in the size of adipose depots and using it to control for body size may have an effect on 178 the correlation between organs. Even if two species have a similar fat-free body mass and body 179 composition, large adipose depots in one species result in organs that seem relatively smaller in 180 comparison to those of a species with smaller adipose depots. Therefore, correlations between 181 organs are mostly positive if we control for whole body mass. This bias is expected to disappear if 182 fat-free body mass is used to control for body size effects (Suppl. Fig. 2).

These relationships were confirmed by our analyses. Brain-organ correlations were mostly 184 positive, if whole body mass was included in the model (Suppl. Tables 4 and 5). Controlling for fat185 free body mass instead of whole body mass reduced or eliminated this bias in most groups, with the 186 notable exception of primates, where positive correlations between organs persist, and brain size is 187 not negatively related to adipose depots mass. We argue (Suppl. Info. 3.6.) that these discrepancies are due to a combination of error and peculiar captivity effects in foregut fermenting primates, and that primates would follow the general mammal trend if more complete data were available. 


\section{References}

1921 Aiello, L. C. \& Wheeler, P. The expensive-tissue hypothesis - the brain and the digestive 193 system in human and primate evolution. Curr. Anthropol. 36, 199-221 (1995).

1942 Mink, J. W., Blumenschine, R. J. \& Adams, D. B. Ratio of central nervous system to body 195 metabolism in vertebrates - its constancy and functional basis. Am. J. Physiol. 241, R203$196 \quad$ R212 (1981).

1973 Bruhn, J. M. \& Benedict, F. G. The respiratory metabolism of the chimpanzee. Proc. Am. $198 \quad$ Acad. Arts Sci. 71, 259-326 (1936).

1994 Wrangham, R. Catching Fire: How Cooking Made Us Human. (Basic Books, New York, 200 2009).

2015 Aiello, L. C., Bates, N. \& Joffe, T. in Evolutionary Anatomy of the Primate Cerebral Cortex 202 (eds Dean, F. \& Gibson, K.) 57-78 (Cambridge University Press, 2001).

2036 Kaufman, J. A., Hladik, C. M. \& Pasquet, P. On the expensive-tissue hypothesis: 204 independent support from highly encephalized fish. Curr. Anthropol. 44, 705-707 (2003).

2057 Isler, K. \& van Schaik, C. P. Costs of encephalisation: the energy trade-off hypothesis tested 206 on birds. J. Hum. Evol. 51, 228-243 (2006).

2078 Jones, K. E. \& MacLarnon, A. M. Affording larger brains: testing hypotheses of mammalian 208 brain evolution on bats. Am. Nat. 164, E20-E31 (2004).

2099 Potts, R. Environmental hypotheses of hominin evolution. Yearb. Phys. Anthropol. 41, 93$210136(1998)$.

21110 Mau, M., Südekum, K.-H. \& Kaiser, T. M. Why cattle feed much and humans think much 212 new approach to confirm the expensive tissue hypothesis by molecular data. Biosci. 213 Hypotheses 2, 205-208 (2009). 
21411 Pfefferle, A. D. et al. Comparative expression analysis of the phosphocreatine circuit in 215 extant primates: implications for human brain evolution. J. Hum. Evol. 60, 205-212 (2011).

21612 Santoro, S. et al. Preliminary results from digestive adaptation: a new surgical proposal for 217 treating obesity, based on physiology and evolution. Sao Paulo Med. J. 124, 192-197 (2006).

21813 Pond, C. M. The Fats of Life (Cambridge University Press, 1998).

21914 Sol, D. Revisiting the cognitive buffer hypothesis for the evolution of large brains. Biol. $220 \quad$ Letters 5, 130-133 (2009).

$221 \quad 15$ van Woerden, J. T., van Schaik, C. P. \& Isler, K. Effects of seasonality on brain size 222 evolution: evidence from strepsirrhine primates. Am. Nat. 176, 758-767 (2010).

22316 Garland, T. Scaling the ecological cost of transport to body mass in terrestrial mammals. Am. $224 \quad$ Nat. 121, 571-587 (1983).

22517 Reader, S. M., Hager, Y. \& Laland, K. N. The evolution of primate general and cultural intelligence. Philos. T. R. Soc. B 366, 1017-1027 (2011).

22718 Martin, R. D. Relative brain size and basal metabolic rate in terrestrial vertebrates. Nature 228 293, 57-60 (1981).

22919 Isler, K. \& van Schaik, C. P. The Expensive Brain: a framework for explaining evolutionary 230 changes in brain size. J. Hum. Evol. 57, 392-400 (2009).

23120 Isler, K. \& van Schaik, C. P. Metabolic costs of brain size evolution. Biol. Letters 2, 557-560 232 (2006).

23321 Isler, K. Energetic trade-offs between brain size and offspring production: marsupials 234 confirm a general mammalian pattern. Bioessays 33, 173-179 (2011).

23522 Wells, J. C. K. The Evolutionary Biology of Human Body Fatness (Cambridge University 236 Press, 2009). 
237

238

239

240

$241 \quad 25$

242

$243 \quad 26$

244

245

246

247

248

249

250

251

252

$253 \quad 3$

254

255

256

257

258

259

23 Zihlman, A. L. in The Pygmy Chimpanzee (ed Susman, R. L.) 179-200 (Plenum Press, 1984).

24 Aiello, L. C. \& Wells, J. C. K. Energetics and the evolution of the genus Homo. Annu. Rev. Anthropol. 31, 323-338 (2002).

25 Kaplan, H., Hill, K., Lancaster, J. \& Hurtado, A. M. A theory of human life history evolution: diet, intelligence, and longevity. Evol. Anthropol. 9, 156-185 (2000).

26 Burkart, J. M., Hrdy, S.B. \& van Schaik, C. P. Cooperative breeding and human cognitive evolution. Evol. Anthropol. 18, 175-186 (2009).

27 Pontzer, H. et al. Locomotor anatomy and biomechanics of the Dmanisi hominins. J. Hum. Evol. 58, 492-504 (2010).

28 Pontzer, H., Raichlen, D. A. \& Sockol, M. D. The metabolic cost of walking in humans, chimpanzees, and early hominins. J. Hum. Evol. 56, 43-54 (2009).

29 Isler, K. \& van Schaik, C. P. Why are there so few smart mammals (but so many smart birds)? Biol. Letters 5, 125-129 (2009).

30 Dean, C. et al. Growth processes in teeth distinguish modern humans from Homo erectus and earlier hominins. Nature 414, 628-631 (2001).

31 Pitts, G. \& Bullard, T. in Body Composition in Animals and Man (ed Reit, J. T.) 45-70 (National Academy of Science Pub No. 1598, 1968).

32 Isler, K. et al. Endocranial volumes of primate species: scaling analyses using a comprehensive and reliable data set. J. Hum. Evol. 55, $967-978$ (2008).

33 Rehkämper, G., Frahm, H. D. \& Zilles, K. Quantitative development of brain and brain structures in birds (Galliformes and Passeriformes) compared to that in mammals (Insectivores and Primates). Brain Behav. Evol. 37, 125-143 (1991). 
26034 Orme, D., Freckleton, R. P., Thomas, G., Petzoldt, T. \& Fritz, S. CAIC: comparative 261 analyses using independent contrasts (2009). 〈http://r-forge.r-project.org/projects/caic〉.

26235 R Development Core Team. R: a language and environment for statistical computing (R 263 Foundation for Statistical Computing, Vienna, 2010).

264 


\section{Supplementary Information}

\section{Excel file}

267 Supplementary Data

268 The file Navarrete_SupplData.xls displays the compiled dataset of organ mass and metabolic data

269 for 100 mammal species.

\section{PDF file}

271 Supplementary Information

272 The file Navarrete_SupplInfo.pdf contains an evaluation of the original anthropoid dataset used to 273 establish the Expensive Tissue Hypothesis, Supplementary Methods, and Supplementary Results 274 and Discussion. 


\section{Acknowledgements}

277 We thank R. D. Martin and J. Wermuth for sharing the Chivers dataset, J. van Woerden for sharing

278 her endocranial volume data, and M. Genoud for sharing his revised compilation of mammalian

279 BMR values. Specimens were provided by numerous institutions, museums and colleagues (Suppl.

280 Info. 2). We acknowledge the valuable input of three anonymous reviewers and Leslie Aiello.

281 Financial support was provided by the Swiss National Science Foundation (grant number 3100A0-

282 117789), the A.H. Schultz-Stiftung and the European Integrated Activities grant SYNTHESYS

283 (grant application number HU-TAF-4916).

285 Author contributions

286 K.I. and C.v.S designed the project. A.N. performed the pilot study and collected the data. A.N. and

287 K.I. performed the analyses and all three authors wrote the manuscript.

289 Author information

290 Reprints and permissions information is available at www.nature.com/reprints. The authors declare 291 no competing financial interests. Readers are welcome to comment on the online version of the 292 article at www.nature.com/nature. Correspondence and requests for materials should be addressed to 293 A.N. (a.navarrete@ aim.uzh.ch) or K.I. (kisler@ aim.uzh.ch). 
296 Table 1: Pair-wise phylogenetic least-squares regression (PGLS) between brain volume and other 297 organ masses, controlling for fat-free body mass. Statistical details and the results of the $\mathrm{N}=45$

298 species subsample are listed in Suppl. Info. 3.1.

\begin{tabular}{lcccc}
\hline & \multicolumn{2}{c}{ Mammals $(\mathbf{N}=\mathbf{1 0 0})$} & \multicolumn{2}{c}{ Primates $(\mathbf{N}=\mathbf{2 3})$} \\
\multicolumn{1}{c}{ Organ } & $\beta$ & $\mathrm{p}$-value & $\beta$ & p-value \\
\hline Heart & 0.15 & 0.13 & $\mathbf{0 . 6 5}$ & $\mathbf{0 . 0 0 7}$ \\
Lungs & -0.03 & 0.73 & 0.44 & 0.07 \\
Kidneys & 0.01 & 0.92 & 0.34 & 0.08 \\
Liver & -0.02 & 0.84 & 0.20 & 0.3 \\
Digestive tract & 0.16 & 0.06 & $\mathbf{0 . 4 8}$ & $\mathbf{0 . 0 0 5}$ \\
\multicolumn{1}{c}{ Stomach } & $\mathbf{0 . 1 5}$ & $\mathbf{0 . 0 4 2}$ & 0.17 & 0.19 \\
\multicolumn{1}{c}{ Intestines } & 0.11 & 0.15 & $\mathbf{0 . 4 1}$ & $\mathbf{0 . 0 0 8}$ \\
Spleen & -0.02 & 0.60 & 0.15 & 0.13 \\
Visceral organs & 0.05 & 0.64 & $\mathbf{0 . 5 0}$ & $\mathbf{0 . 0 2 9}$ \\
Adipose depots & $\mathbf{- 0 . 0 7}$ & $\mathbf{0 . 0 1 7}$ & -0.01 & 0.92 \\
\hline
\end{tabular}


301 Figure 1: Correlations between the masses of visceral organs, brains and adipose depots in a sample 302 of 100 mammal species, controlling for phylogenetic relationships and fat-free body mass.

303 Statistical details are listed in the Suppl. Info. 3.1.

$304 \quad$ Navarrete_fig1.jpg

305 Figure 2: Regression of residual brain mass vs. residual adipose depots mass in wild-caught female 306 mammals, controlling for fat-free body mass (raw data: residual $\ln$ (adipose depots) $=0$ -

$3071.21 *$ residual $\ln$ (brain mass); $\mathrm{N}=28$ species, $\mathrm{p}=0.006, \mathrm{r}^{2}=0.258$; PGLS: $\lambda=1.00, \beta=-0.12$, $\mathrm{t}$-value=$3083.42, \mathrm{p}=0.002)$.

309 Navarrete_fig2.jpg

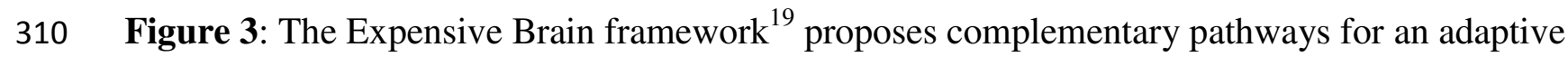
311 increase in relative brain size. First, brains can get larger when energy inputs are stabilized on a 312 higher level (higher total metabolic turnover ${ }^{20}$ ) through an increase in mean dietary quality (e.g. 313 more animal fat and protein in early $\mathrm{Homo}^{4,22,24}$ ), energy subsidies from other individuals (e.g. 314 cooperative breeding, allomaternal care ${ }^{19,21}$ ) or by reducing fluctuations in energy inputs (e.g. 315 cognitive solutions ${ }^{15}$ including culture). Second, at constant total energy intake, energy allocation to 316 other functions may be reduced, such as locomotion (e.g. efficient bipedalism ${ }^{27,28}$ ) or production 317 (e.g. slower life history pace ${ }^{30}$ ).

318 Navarrete_fig3.jpg 


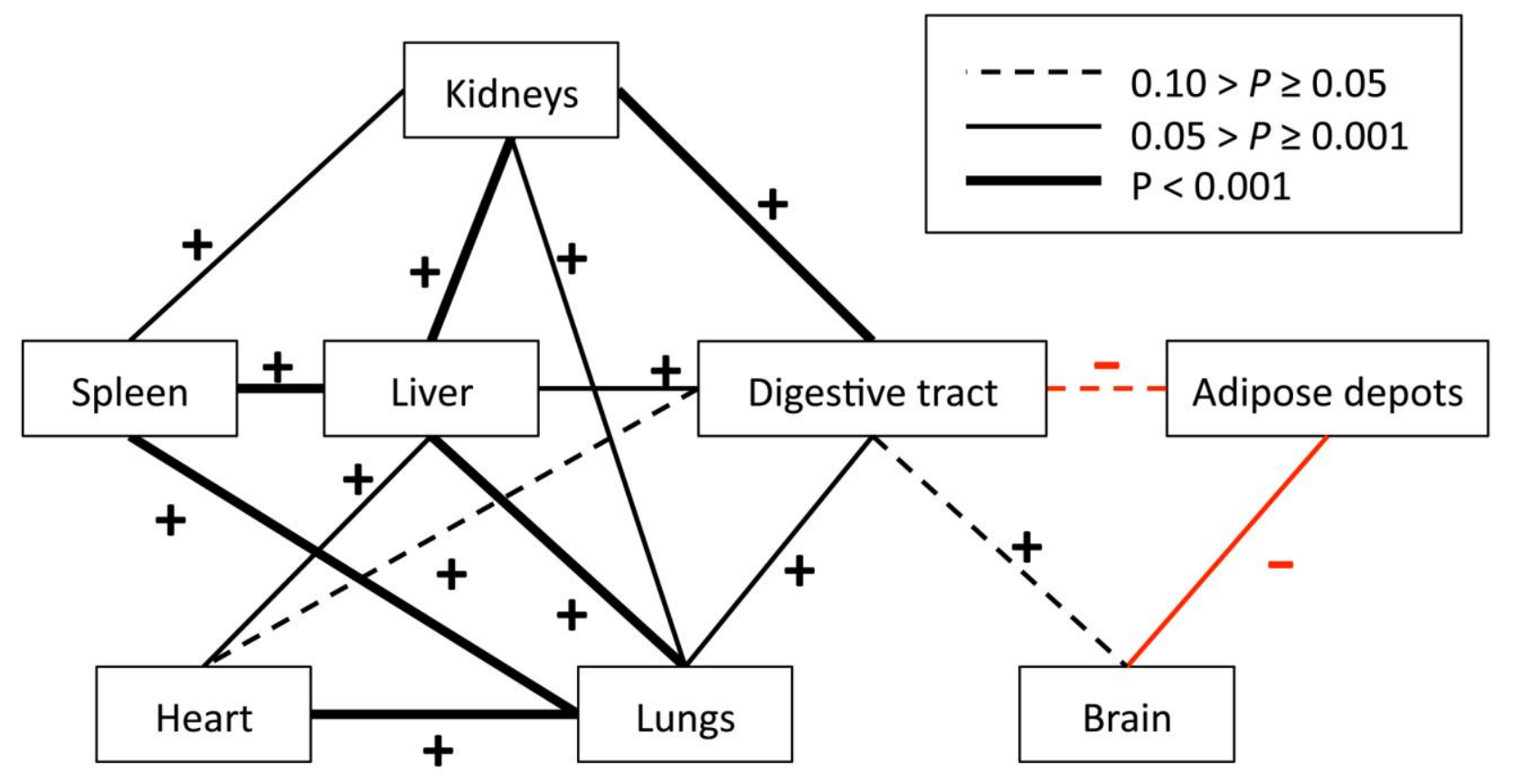




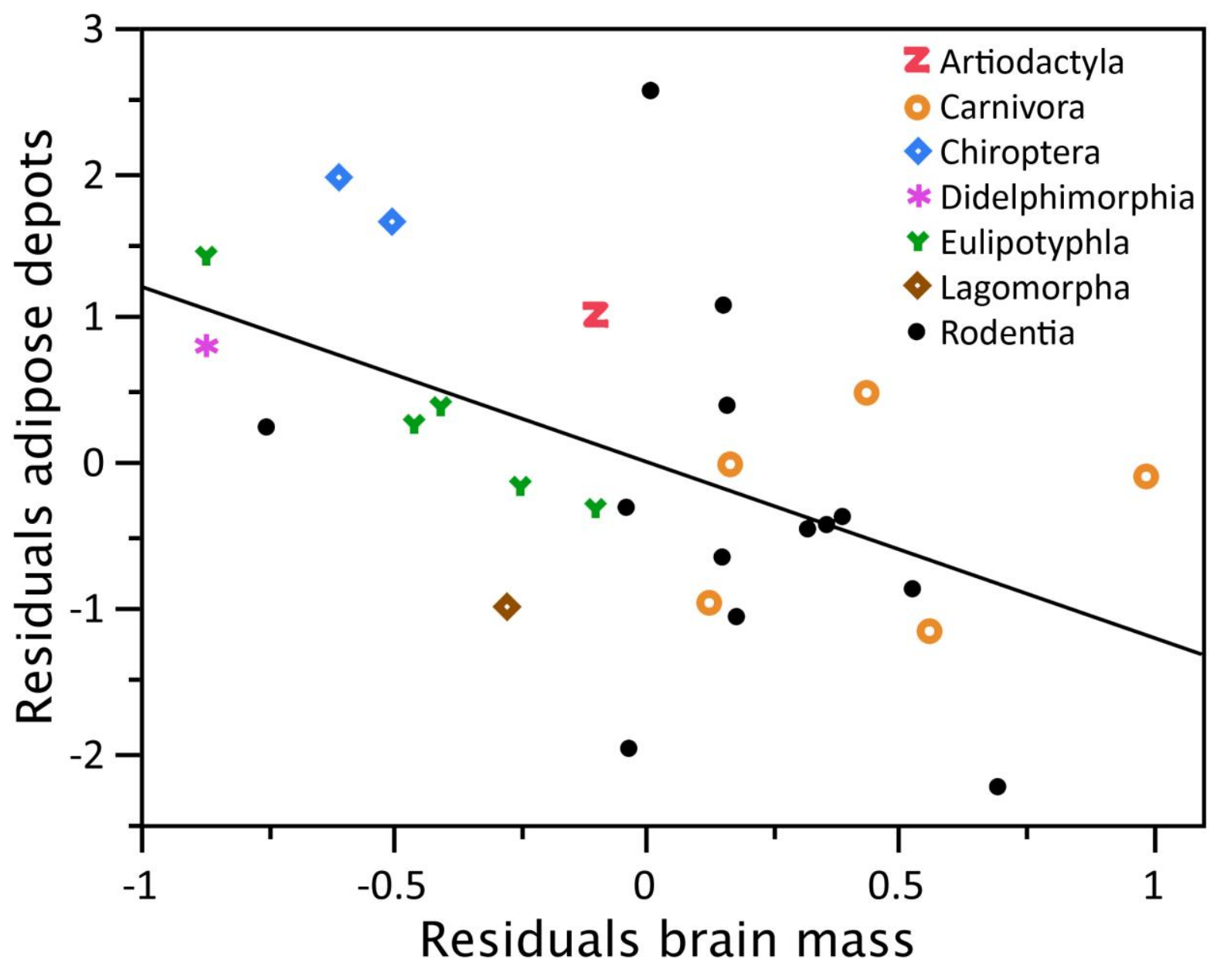




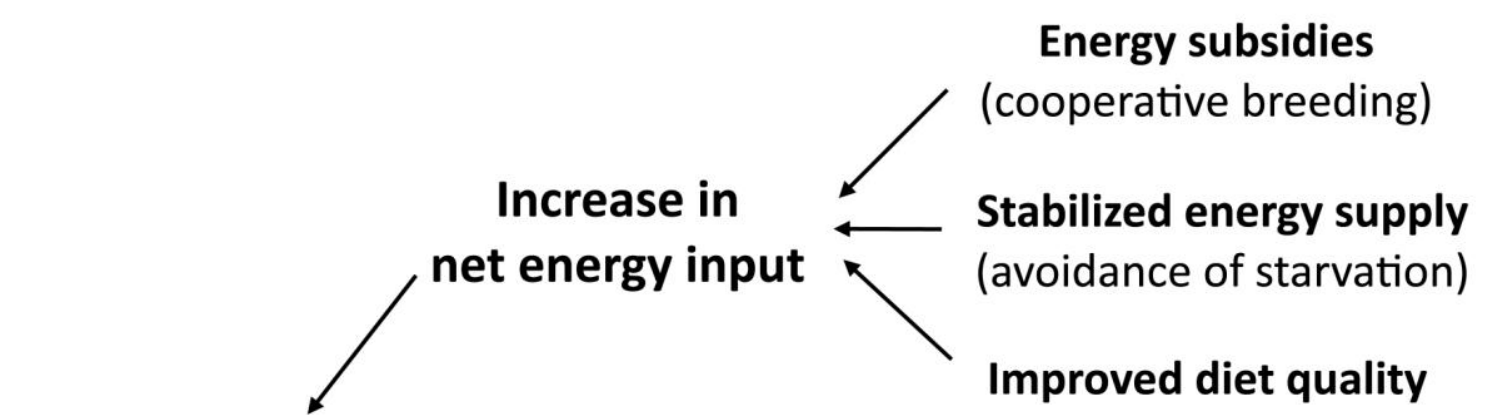

\section{Larger brain}

(relative to body size)

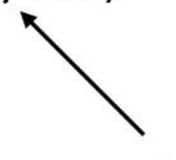

Change in energy allocation

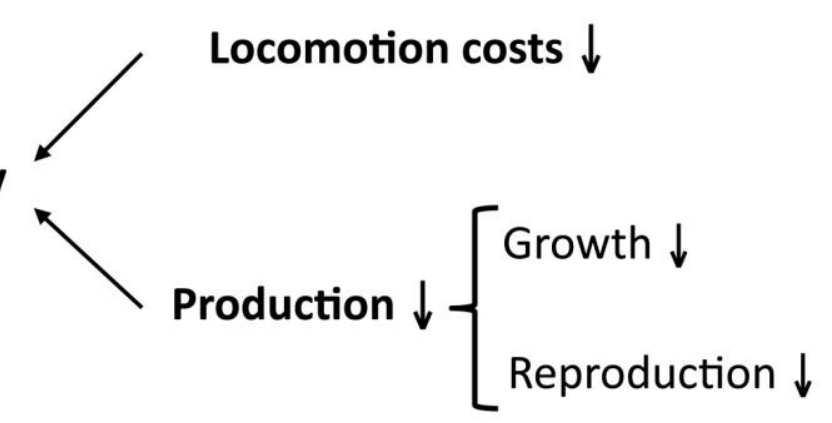


Energetics and the evolution of human brain size: no gut-brain trade-off in mammals

Ana F. Navarrete, Carel P. van Schaik, Karin Isler

\section{Supplementary Information}

\section{Content}

1. Evaluation of the original anthropoid dataset to establish the Expensive Tissue Hypothesis

\section{Supplementary results and discussion}

3.1. Extended results, including the $\mathrm{N}=45$ species subsample 12

$\begin{array}{ll}\text { 3.2. Dataset composition } & \text { p. } 17\end{array}$

3.3. An alternative method to estimate total adipose depots mass 19

3.4. Reducing error variation by splitting the sample into wild/captive, and male/female $\begin{array}{ll}\text { subsamples } & \text { p. } 20\end{array}$

$\begin{array}{ll}\text { 3.5. Potential autocorrelation effects and compositional data analysis } & \text { p. } 22\end{array}$

$\begin{array}{ll}3.6 . & \text { The special case of primates } 26\end{array}$

$\begin{array}{ll}\text { 3.7. Costs of transporting adipose depots } & \text { p. } 28\end{array}$

$\begin{array}{lr}\text { Supplementary References } & \text { p. } 30\end{array}$

\section{Other Supplementary Files}

Navarrete_SupplData.xls

Note for all tables: $\lambda:$ ML-estimate of lambda, $\beta$ : PGLS estimate of the effect size. If the lambda value is not significantly different from both 0 and 1 (italics), both classic independent contrasts and raw species regressions are shown additionally. $\mathrm{P}$ values $<0.05$ are shown in bold face. 


\section{Supplementary Information 1: Evaluation of the original anthropoid dataset to establish the Expensive Tissue Hypothesis}

\section{Introduction}

In addition to compiling and analyzing our own dataset, we also conducted a detailed evaluation of the original study that supported the Expensive Tissue Hypothesis in anthropoid primates ${ }^{1}$. Their original analysis was based on combining the digestive tract and body mass data from Chivers and Hladik ${ }^{36}$ with brain size and body mass data from Harvey and Clutton-Brock ${ }^{37}$ for anthropoid primates. The Chivers dataset included individual mass and surface area measurements from several components of the digestive tract (stomach, ileum, caecum and colon) as well as body mass in a sample of 157 mammalian specimens, including 37 primate species (the published data were corrected for a layout error, and complemented by the full list of measurements made available by D. Chivers to R.D. Martin and L. Aiello). Aiello and Wheeler analyzed the anthropoid species from this dataset and published their species averages several years later ${ }^{5}$ (Suppl. Table 2). The original analysis of Aiello and Wheeler yielded a negative correlation between brain size and digestive tract mass (the sum of stomach, ileum, caecum and colon mass), controlling for the effect of body mass $(\mathrm{N}=18, \mathrm{r}=-0.69, P<0.001)$. This negative correlation persisted when Homo sapiens was excluded from the sample ${ }^{5}(\mathrm{n}=17, \mathrm{r}-0.62, P=$ 0.007).

In this evaluation, we use the Chivers and Hladik dataset to test the Expensive Tissue Hypothesis, making full use of current phylogenetic methodology ${ }^{34}$ and more accurate sexspecific brain volume and body mass data that have become available in recent years ${ }^{15,32}$.

\section{Methods}

Individual measurements of digestive tract mass were taken from the full Chivers dataset, after the exclusion of individuals suspected to be emaciated or immature. Brain volume and body mass from wild-caught adult primates were obtained from published sources ${ }^{15,32}$ and additional measurements by J. van Woerden (pers. comm.).

The original study correlated brain mass with gut mass, i.e. digestive tract mass, described as the sum of the masses of stomach, ileum, caecum and colon. In this evaluation, we correlated brain mass with stomach mass, intestine mass (described as the sum of ileum, caecum and colon) and digestive tract mass. Because brains and digestive tract measures were obtained from 
different specimens, a major challenge is to deal with the variability in body mass within species and the resulting error of estimating the relative size of organs. In order to obtain an optimum correspondence between digestive tract and brain specimens, we included only adults that were not emaciated as compared to average body mass values for the respective sex (body mass more than $75 \%$ of the average mass). To preclude confounding effects of body mass dimorphism between the sexes, we adhered to the following rationale: first, we calculated the averages for the digestive tract variables for each species, while recording whether the average included only females, only males or both sexes. Second, brain mass was paired to the digestive tract values as follows: for species with no sexual dimorphism in body mass (less than 10\% difference between males and females), we took the average brain mass for both sexes; otherwise, we took the average brain mass for the same sex or the whole species depending on the sex of the individuals included in the digestive tract averages. Our final sample included $\mathrm{N}=23$ anthropoid species and $\mathrm{N}=2$ strepsirrhines (Suppl. Table 2).

All variables were log-transformed and phylogenetic regressions (PGLS) were run using pglmEstLambda in the CAIC package ${ }^{34}$ in $\mathrm{R}^{35}$ with the consensus tree from the $10 \mathrm{kTrees}$ project $^{38}$. As the small sample size yielded unstable estimates of lambda in some cases (lambda not significantly different from either 0 or 1 ), we also ran all analyses with lambda set to 0 (raw data) or 1 (classic independent contrasts). The phylogenetic least-squares regression model included both body masses and the digestive tract mass as independent variables and brain mass as the dependent variable.

\section{Results and discussion}

In contrast to the original result of Aiello and Wheeler ${ }^{1}$, our revised sample did not yield any significantly negative correlations between brain and one of the digestive tract variables or the combined digestive tract mass (Suppl. Table 1). Results did not differ according to whether phylogenetic information was taken into account or not, and whether the two strepsirrhine species were included or not.

There are various reasons for the discrepancy between these results and the originally reported negative correlation. First, the Harvey dataset reported some brain size values that were not confirmed for some species in subsequent reports, and sometimes reported only male values without mentioning this fact. Second, sexual size dimorphism affects body mass more than brain mass $^{39}$, which may confound analyses where sex is not taken into account. Third, brain size data 
have become available for more platyrrhine species in recent years, reducing the bias toward catarrhine species in the original analysis. Fourth, we excluded clearly emaciated individuals of the Chivers dataset in our analysis. In conclusion, matching the best available brain and body mass data with the Chivers dataset does not yield support for the Expensive Tissue Hypothesis in anthropoid primates.

Supplementary Table 1: Correlations between brain mass residuals and the residuals of mass of stomach, intestines and digestive tract (sum of stomach and intestines).

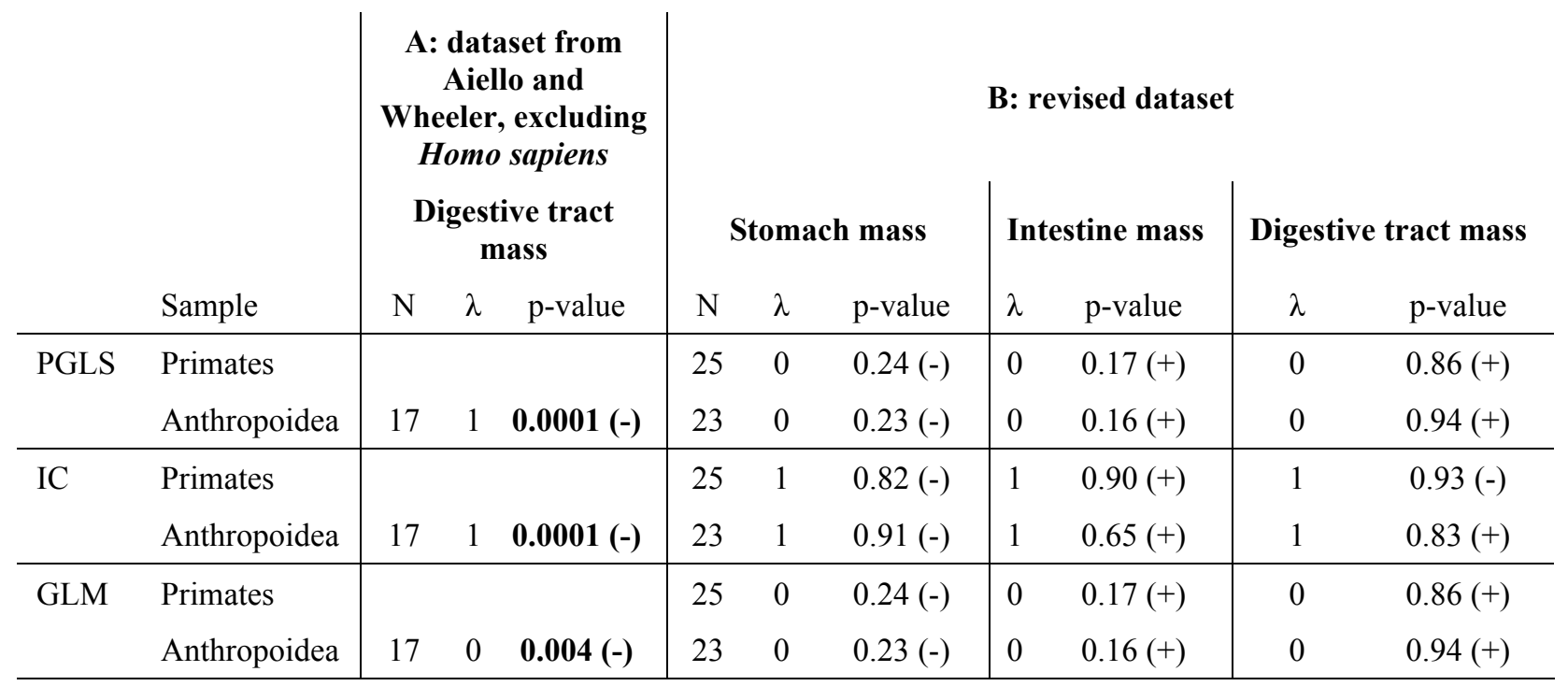

PGLS: phylogenetic least-squares methods, IC: classic independent contrasts (lambda set to 1), GLM: linear model of logged species data (lambda set to 0$)$. (+) indicates a positive correlation, $(-)$ indicates a negative correlation. Significant $\mathrm{p}$-values are shown in bold face. 
Supplementary Table 2: The two datasets based on the digestive tract mass data from Chivers and Hladik ${ }^{36}$.

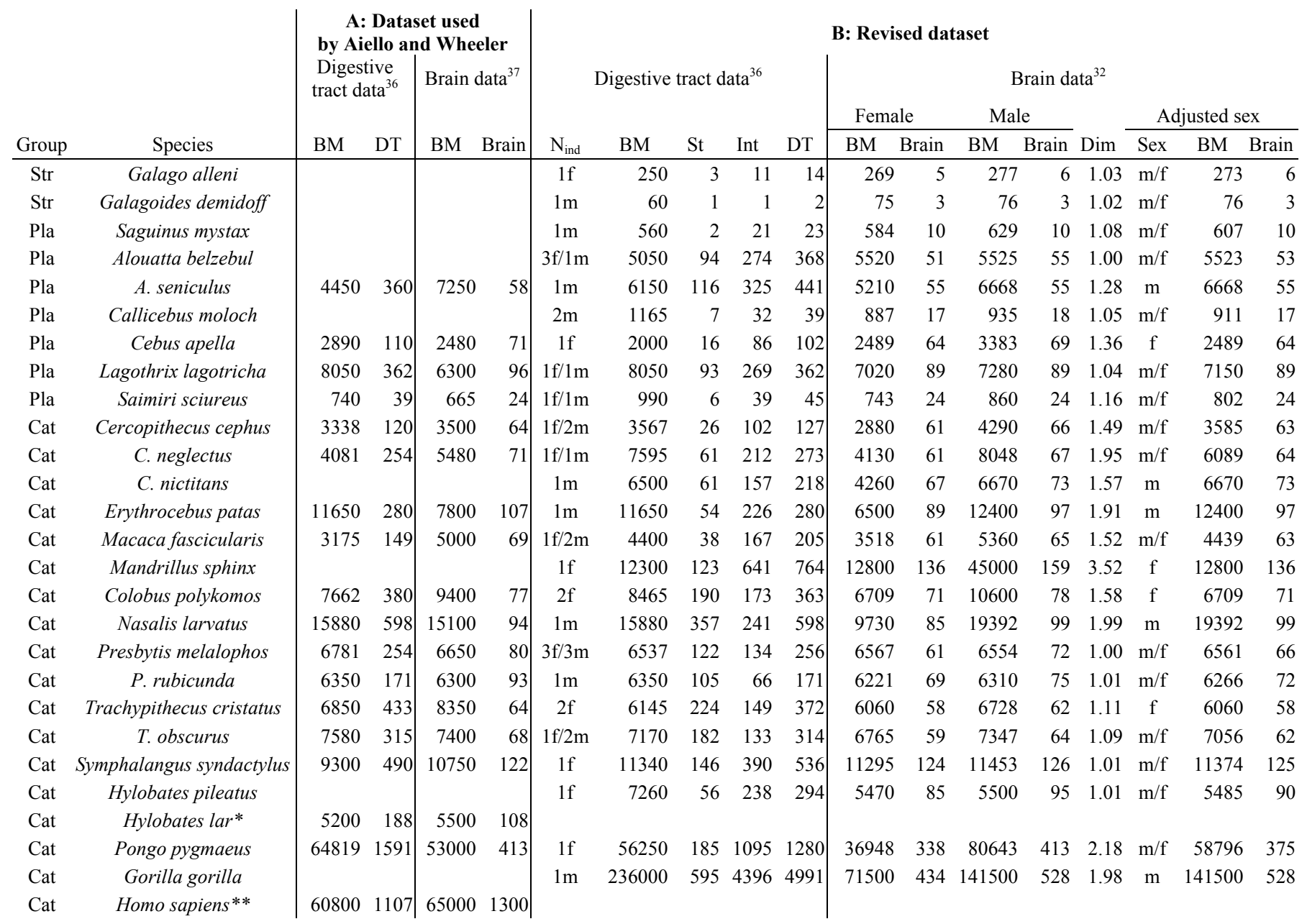

All values are in grams. Stre: strepsirrhine, Pla: platyrrhines, Cat: catarrhines, BM: body mass, DT: digestive tract, St: stomach, Int: intestines, $\mathrm{N}_{\text {ind }}$ : number of individuals used in the average, Dim: index of sexual dimorphism in body mass $\left(\mathrm{BM}_{\text {male }} / \mathrm{BM}_{\text {female }}\right)$. $\mathrm{m} / \mathrm{f}$ : average of male and female values.

* Hylobates lar: excluded because the specimens were "fixed", which may influence organ masses.

** Testing the Expensive Tissue Hypothesis as a general pattern to explain the Pan-Homo distinction requires that Homo sapiens is excluded from the comparison. The Homo values in the Aiello and Wheeler sample were taken from Ashoff et al. ${ }^{40}$, presumably because the body mass value of the Chivers individuals is very low $(45 \mathrm{~kg})$. 


\section{Supplementary Information 2: Supplementary Methods}

This section contains a dissection protocol, the calculation of total adipose depots mass from abdominal adipose depots mass (Suppl. Figure 1), a rationale for how to control for the effect of body size (Suppl. Figure 2), and the phylogenetic tree (Suppl. Figure 3).

\section{Specimens}

Cadavers were collected from various museums, zoos and donors: Naturhistorisches Museum Basel, Naturhistorisches Museum Fribourg, Muséum d'Histoire Naturelle Genève, Muséum d'Histoire Naturelle Neuchâtel, Zoologisches Museum der Universität Zürich, Zoo Zürich, Knies Kinderzoo Rapperswil, Igelzentrum Zürich, Wildpark Langenberg, Dr. Marcus Clauss, Alexander Schweiger, Dr. Anna Lindholm, Dr. Carsten Schradin, Heinz Galli (all CH), Naturhistorisches Museum Mainz, Staatliches Museum für Naturkunde Stuttgart, Wilhelm and Helga Klemens, Elke Kissel (all DE), Zoo Antwerpen (NL), Royal Museum of African Fauna Tervuren (BE), National Museums of Scotland (UK), Hungarian Natural History Museum (HU), and the Field Museum of Natural History (USA).

\section{Dissection protocol}

Information about sex, age, origin, time and cause of death of the specimens was collected when available. Museum staff performed skinning and bone preparation if the specimens were to be prepared for their collections. Specimens from the National Museums of Scotland were prepared for dissection by G. Hantke by removing the bulk of all visceral organs, and keeping them frozen in a sealed plastic bag until A. Navarrete performed the dissections. All other cadavers were dissected by A. Navarrete.

Preparations: Frozen specimens were allowed to thaw ( $2 \mathrm{~h}$ for small specimens, overnight for large specimens) and external moisture on the skin was removed using a hair dryer. The total body mass was weighed when the body temperature equaled ambient temperature. The specimens were skinned and the skin was weighed. To avoid desiccation, the organs were put onto a wet paper towel immediately after removal. For weighing, individual organs were put onto small sheets of aluminum (small specimens) or into plastic containers (larger specimens), and net weights determined. All weights were recorded in grams.

Abdominal cavity: The testes were removed in male specimens. The abdominal cavity was opened with a ventral cut from sternum to pubis and two transverse cuts along the distal end 
of the rib cage. The spleen was removed. The small intestine was shifted aside, and the kidneys and additional male sexual structures (seminal vesicles) were cut off and removed. The adrenal glands were separated from the kidneys. The digestive tract was removed cutting the esophagus at the level of the diaphragm and cutting the anus and, in females, the vulva. The female sexual organs were removed. The liver and pancreas were removed. The digestive tract (stomach and intestines) was cleaned from connective and adipose tissue, laid on millimeter paper and photographed. Stomach, ileum, caecum and colon were separated, weighed a first time, cut open to remove contents, washed, dried with a paper towel after washing to remove excess water and weighed empty a second time. The other abdominal organs were weighed.

Thoracic cavity: The diaphragm was cut open following the inner rib cage line. Trachea and esophagus were cut above the sternum, and connective tissue was loosened to allow the thoracic organs to be pulled out distally. The heart was separated, opened and the chambers were cleaned of blood coagulations by rinsing. The lungs were separated by cutting the bronchi. The thoracic organs were weighed.

Adipose depots: During dissection, visible subcutaneous and intermuscular accumulations of adipose depots were continuously removed and put in a separate container. Adipose depots were removed from the walls of the abdominal and thoracic cavities, and from between the visceral organs. The total adipose depots were weighed. For 45 species in our sample, adipose depots of the whole body were measured directly. For the other 55 species, only abdominal adipose depots were measured, from which we calculated a proxy of total adipose depots by scaling the abdominal depots mass with a factor 3.419. This scaling factor was derived from a comparison of the two measurements for all individuals for which body mass and one of the two adipose depots measurements was available (Suppl. Figure 1). Fat-free body mass was calculated as whole body mass minus total adipose depots mass. The rationale on the usage of fat-free body mass to control for differences in body size between species is illustrated in Suppl. Figure 2 .

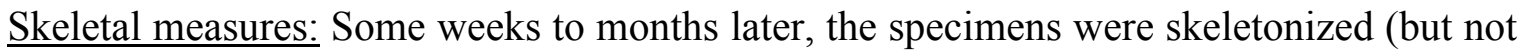
degreased), and the bones were dried and weighed. The cranial capacity was determined using the seed filling method ${ }^{32}$, and converted into an estimate of brain mass by multiplying the volume with $1.036^{33}$. 


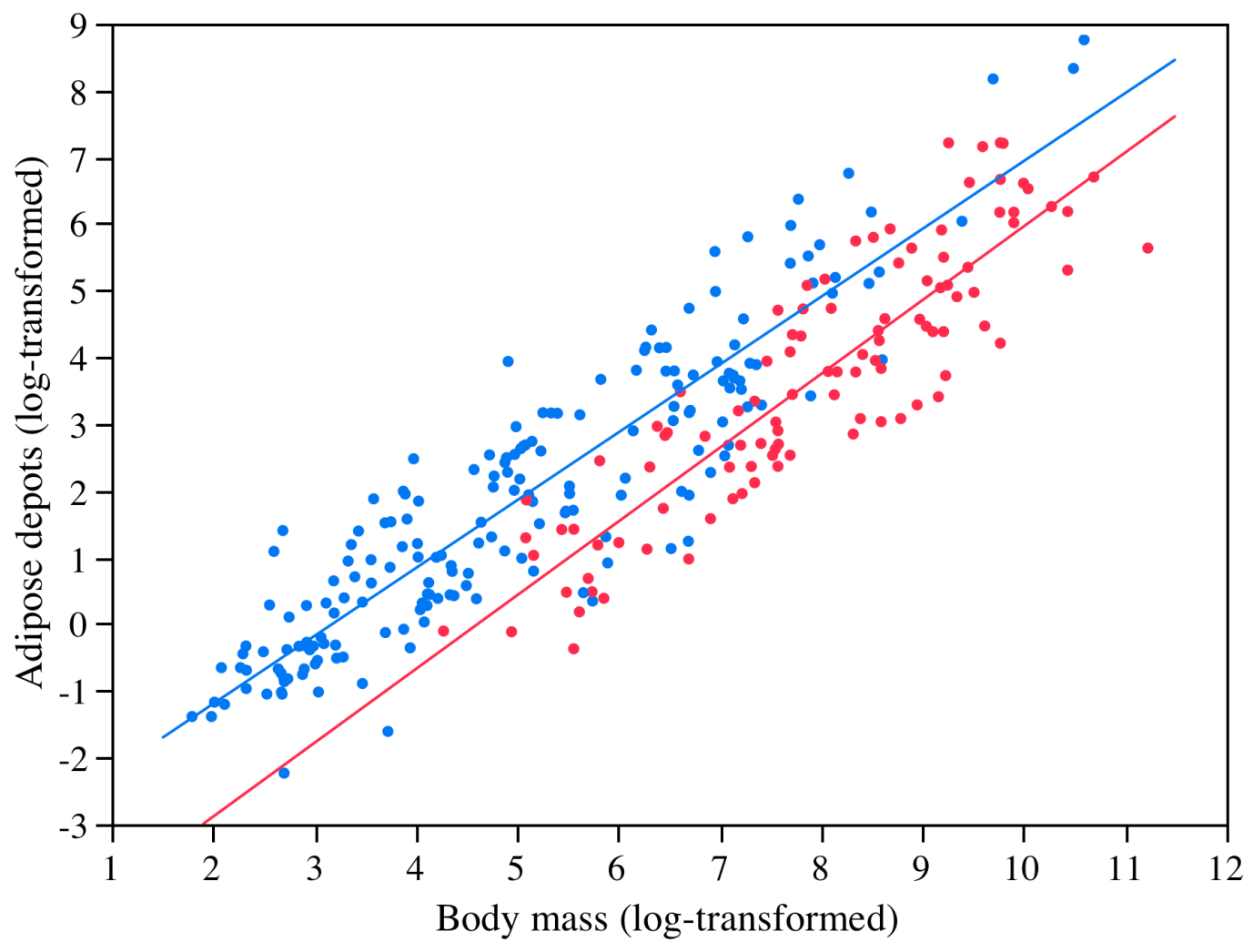

Supplementary Figure 1: Regression of adipose depots mass on body mass for 292 specimens. The slopes of the least-squares regression of total adipose depots (blue symbols) vs. body mass (ln(total fat): $-3.233+1.017 \ln$ (body mass), $\mathrm{N}=188$ ) and the least-squares regression of abdominal adipose depots (red symbols) vs. body mass ( $\ln$ (abdominal fat): $-5.103+1.106 \ln$ (body mass), $\mathrm{N}=104$ ) did not differ significantly from each other. Thus, a common slope of 1.0401 was fitted to both subsamples $(\ln ($ abdominal fat): $-4.578+1.0401 \ln$ (body mass), $N=104 ; \ln ($ total fat): $3.348+1.0401 \ln$ (body mass), $\mathrm{N}=188$ ), and the scaling factor was derived from the intercept difference, $1 / \exp (-4.5775+3.3482)=3.419$. Using fat-free body mass would yield a very similar correction factor of 3.46. An alternative method is described in Section 3.3. 
A Model species

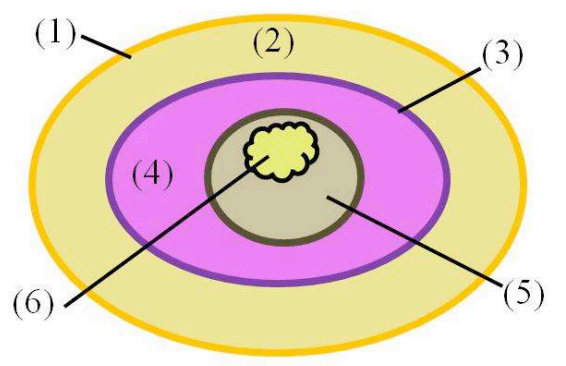

(1) Whole body mass

(2) Adipose depots

(3) Fat-free body mass

(4) Non-visceral tissue

(5) Visceral tissue

(6) Brain mass

B

Species 1

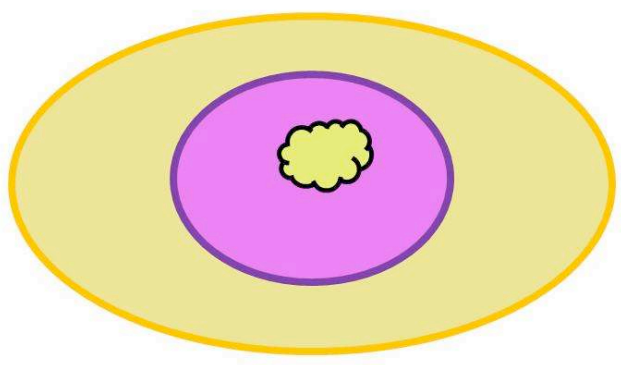

Larger adipose depots

Larger body mass
Species 2

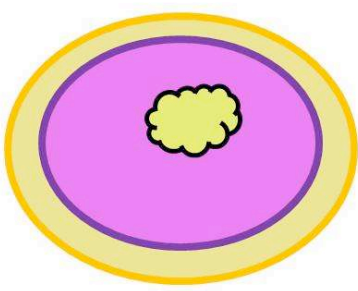

Smaller adipose depots

Smaller body mass

When corrected by whole body mass:

Smaller visceral mass

Smaller brain mass

C

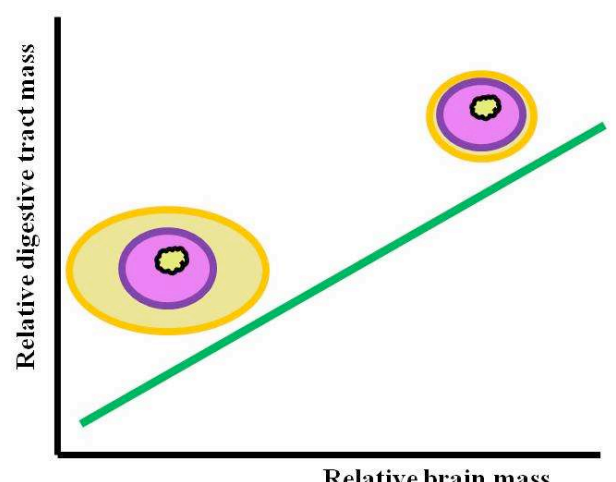

Controlling for whole body mass
Larger visceral mass

Larger brain mass
D

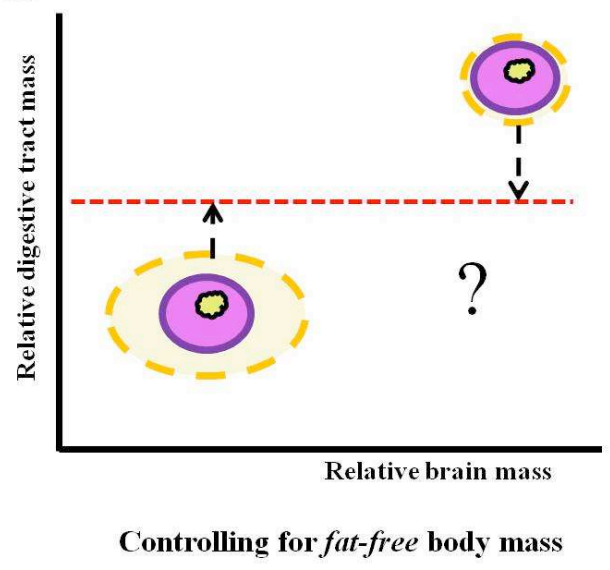

Supplementary Figure 2: The rationale for controlling for body size by using fat-free body mass. A species is depicted by its body composition (A). Two species may have the same fat-free body mass, but different amounts of adipose depots (B). Controlling for whole body mass yields positive correlations between organ masses (C). Only controlling for fat-free body mass allows us to detect a possible trade-off between the sizes of different organs (D). 


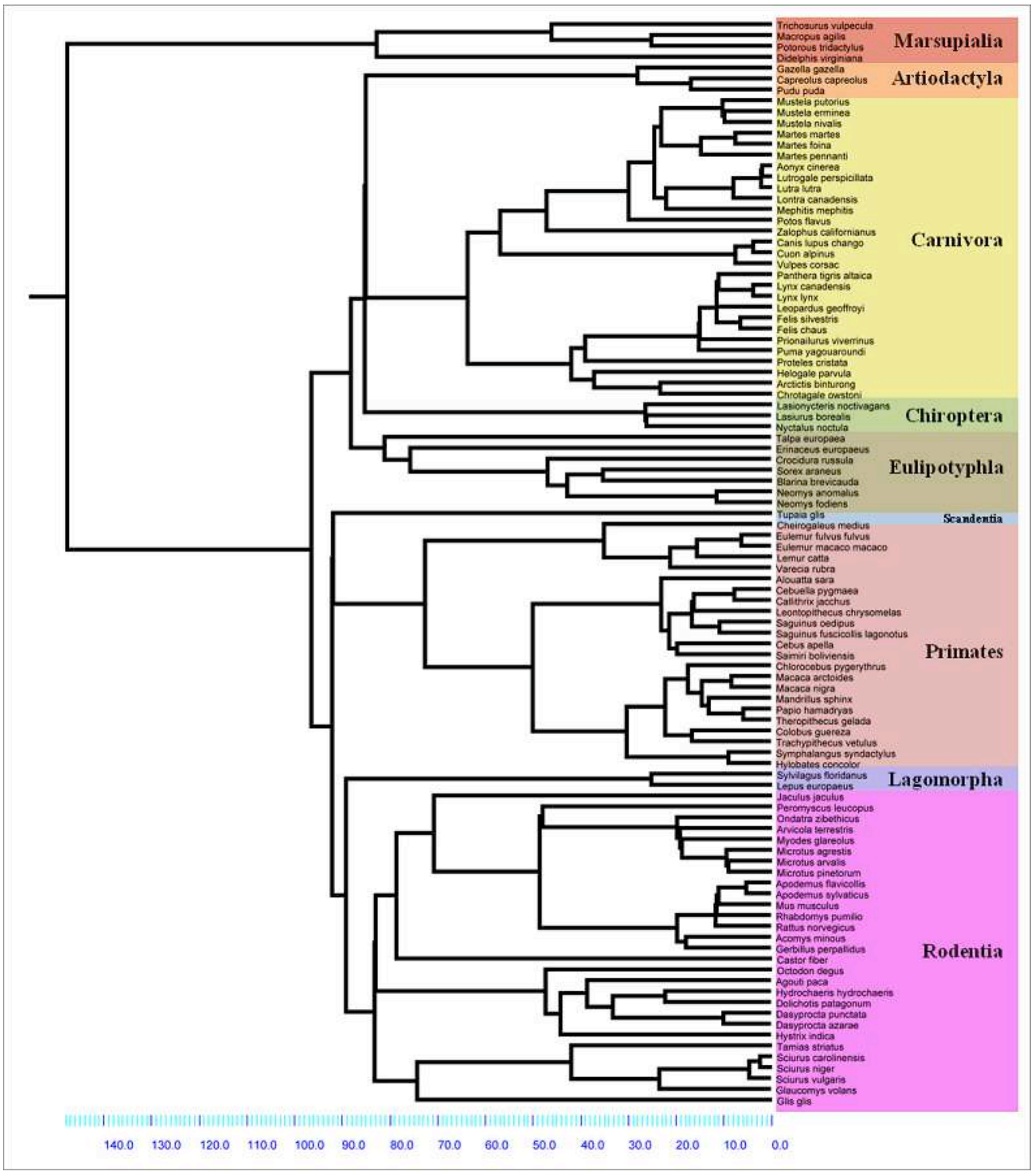

Supplementary Figure 3: Phylogenetic tree of the 100 mammal species in our sample, mainly from Bininda-Emonds et al. ${ }^{41}$. Distances are given in million years before present. As the phylogenetic generalized least-squares method (PGLS) requires a completely resolved 
phylogeny, polytomies were resolved using various sources. Within Chiroptera, Lasiurus and Nyctalus are more closely related to each other than to Lasionycteris according to Volleth and Heller $^{42}$. Within Carnivora, polytomies in the Lutrinae group were resolved using Koepfli et al. ${ }^{43}$. Within Rodentia, the phylogeny of Cricetidae follows Robovský et al. ${ }^{44}$, the one of Muridae follows Lecompte et al. ${ }^{45}$, and the distance between Cricetidae and Muridae was taken from Michaux et al. ${ }^{46}$. Within Caviidae, distances were taken from Rowe and Honeycutt ${ }^{47}$ and Veniaminova et al. ${ }^{48}$. Distances within Primates were modified following Arnold et al. ${ }^{38}$. 


\section{Supplementary Information 3: Supplementary results and discussion}

\subsection{Extended results, including the $\mathrm{N}=45$ species subsample}

This section contains the correlation matrix for all organs used for Figure 2 in the main text (Suppl. Table 3), full statistics for the results shown in Table 1 in the main text (Suppl. Table 4), and additional results for the 45-species sample with known total adipose depots mass (Suppl. Table 5).

Supplementary Table 3: Pair-wise correlation matrix including brain, visceral organs, and adipose depots mass. All correlations are controlled for fat-free body mass and calculated by PGLS.

\begin{tabular}{|c|c|c|c|c|c|c|c|c|c|}
\hline & Heart & Lungs & Kidneys & Liver & $\begin{array}{c}\text { Digestive } \\
\text { tract }\end{array}$ & Stomach & Intestines & Spleen & $\begin{array}{c}\text { Adipose } \\
\text { depots }\end{array}$ \\
\hline Brain & $\begin{array}{l}\beta=0.15 \\
P=0.13\end{array}$ & $\begin{array}{l}\beta=-0.03 \\
P=0.73\end{array}$ & $\begin{array}{l}\beta=0.01 \\
P=0.92\end{array}$ & $\begin{array}{l}\beta=-0.02 \\
P=0.85\end{array}$ & $\begin{array}{l}\beta=0.16 \\
P=0.06\end{array}$ & $\begin{array}{c}\beta=0.15 \\
\mathbf{P}=\mathbf{0 . 0 4 2}\end{array}$ & $\begin{array}{l}\beta=0.11 \\
\mathrm{P}=0.15\end{array}$ & $\begin{array}{l}\beta=-0.02 \\
P=0.60\end{array}$ & $\begin{array}{l}\beta=-0.07 \\
\mathbf{P}=\mathbf{0 . 0 1 7}\end{array}$ \\
\hline Heart & & $\begin{array}{c}\beta=0.63 \\
\mathbf{P}<\mathbf{0 . 0 0 0 1}\end{array}$ & $\begin{array}{l}\beta=0.15 \\
P=0.13\end{array}$ & $\begin{array}{c}\beta=0.18 \\
\mathbf{P}=\mathbf{0 . 0 3 5}\end{array}$ & $\begin{array}{l}\beta=0.16 \\
P=0.09\end{array}$ & $\begin{array}{l}\beta=0.08 \\
P=0.27\end{array}$ & $\begin{array}{l}\beta=0.12 \\
P=0.13\end{array}$ & $\begin{array}{l}\beta=0.05 \\
P=0.15\end{array}$ & $\begin{array}{l}\beta=-0.03 \\
P=0.32\end{array}$ \\
\hline Lungs & & & $\begin{array}{l}\beta=0.27 \\
\mathbf{P}=\mathbf{0 . 0 0 4}\end{array}$ & $\begin{array}{c}\beta=0.32 \\
\mathbf{P}<\mathbf{0 . 0 0 0 1}\end{array}$ & $\begin{array}{c}\beta=0.18 \\
\mathbf{P}=\mathbf{0 . 0 4 2}\end{array}$ & $\begin{array}{l}\beta=0.06 \\
\mathrm{P}=0.36\end{array}$ & $\begin{array}{l}\beta=0.14 \\
\mathrm{P}=0.07\end{array}$ & $\begin{array}{c}\beta=0.13 \\
\mathbf{P}<\mathbf{0 . 0 0 0 1}\end{array}$ & $\begin{array}{c}\beta=-0.003 \\
P=0.93\end{array}$ \\
\hline Kidneys & & & & $\begin{array}{c}\beta=0.45 \\
\mathbf{P}<\mathbf{0 . 0 0 0 1}\end{array}$ & $\begin{array}{c}\beta=0.29 \\
\mathbf{P}=\mathbf{0 . 0 0 2}\end{array}$ & $\begin{array}{l}\beta=0.06 \\
P=0.40\end{array}$ & $\begin{array}{c}\beta=0.28 \\
\mathbf{P}=\mathbf{0 . 0 0 0 2}\end{array}$ & $\begin{array}{c}\beta=0.11 \\
\mathbf{P}=\mathbf{0 . 0 0 3}\end{array}$ & $\begin{array}{c}\beta=0.005 \\
P=0.88\end{array}$ \\
\hline Liver & & & & & $\begin{aligned} \beta & =0.30 \\
\mathbf{P} & =\mathbf{0 . 0 0 5}\end{aligned}$ & $\begin{array}{l}\beta=0.06 \\
P=0.43\end{array}$ & $\begin{array}{c}\beta=0.26 \\
\mathbf{P}=\mathbf{0 . 0 0 4}\end{array}$ & $\begin{array}{c}\beta=0.15 \\
\mathbf{P}<\mathbf{0 . 0 0 0 1}\end{array}$ & $\begin{array}{l}\beta=-0.01 \\
P=0.74\end{array}$ \\
\hline $\begin{array}{l}\text { Digestive } \\
\text { tract }\end{array}$ & & & & & & $\begin{array}{c}\beta=0.53 \\
\mathbf{P}<\mathbf{0 . 0 0 0 1}\end{array}$ & $\begin{array}{c}\beta=0.81 \\
\mathbf{P}<\mathbf{0 . 0 0 0 1}\end{array}$ & $\begin{array}{l}\beta=0.05 \\
P=0.19\end{array}$ & $\begin{array}{l}\beta=-0.07 \\
P=0.07\end{array}$ \\
\hline Stomach & & & & & & & $\begin{array}{c}\beta=0.39 \\
\mathbf{P}<\mathbf{0 . 0 0 0 1}\end{array}$ & $\begin{array}{l}\beta=0.04 \\
P=0.37\end{array}$ & $\begin{array}{l}\beta=-0.03 \\
P=0.55\end{array}$ \\
\hline Intestine & & & & & & & & $\begin{array}{l}\beta=0.04 \\
\mathrm{P}=0.39\end{array}$ & $\begin{array}{l}\beta=-0.11 \\
\mathbf{P}=\mathbf{0 . 0 1 3}\end{array}$ \\
\hline Spleen & & & & & & & & & $\begin{array}{l}\beta=0.11 \\
P=0.24\end{array}$ \\
\hline
\end{tabular}


Supplementary Table 4: Pair-wise phylogenetic least-squares regression (PGLS) between brain and other organ masses $(\mathrm{N}=100$ species $)$, controlling for a) fat-free body mass, and $\mathrm{b}$ ) whole body mass.

\begin{tabular}{|c|c|c|c|c|c|c|c|c|c|c|c|c|}
\hline \multirow{3}{*}{$\begin{array}{c}\text { a) } \\
\text { Organ }\end{array}$} & \multicolumn{12}{|c|}{ Including fat-free body mass as covariate } \\
\hline & \multicolumn{6}{|c|}{ PGLS } & \multicolumn{3}{|c|}{$\begin{array}{c}\text { Independent contrasts } \\
(\lambda=1)\end{array}$} & \multicolumn{3}{|c|}{$\begin{array}{c}\text { Raw data } \\
(\lambda=0)\end{array}$} \\
\hline & $\lambda$ & $\mathrm{P}(\lambda=0)$ & $\mathrm{P}(\lambda=1)$ & $\beta$ & t-value & $\mathrm{p}$-value & $\beta$ & t-value & p-value & $\beta$ & t-value & p-value \\
\hline Mammals & $\mathrm{N}=\mathbf{1 0 0}$ & & & & & & & & & & & \\
\hline Heart & 0.918 & $<0.0001$ & 0.001 & 0.15 & 1.51 & 0.13 & & & & & & \\
\hline Lungs & 0.928 & $<0.0001$ & 0.010 & -0.03 & -0.35 & 0.73 & & & & & & \\
\hline Kidneys & 0.921 & $<0.0001$ & 0.004 & 0.01 & 0.10 & 0.92 & & & & & & \\
\hline Liver & 0.923 & $<0.0001$ & 0.005 & -0.02 & -0.19 & 0.84 & & & & & & \\
\hline Digestive tract & 0.943 & $<0.0001$ & 0.007 & 0.16 & 1.89 & 0.06 & & & & & & \\
\hline Stomach & 0.934 & $<0.0001$ & 0.005 & 0.15 & 2.06 & 0.042 & & & & & & \\
\hline Intestine & 0.940 & $<0.0001$ & 0.007 & 0.11 & 1.45 & 0.15 & & & & & & \\
\hline Spleen & 0.929 & $<0.0001$ & 0.008 & -0.02 & -0.53 & 0.60 & & & & & & \\
\hline Visceral organs & 0.922 & $<0.0001$ & 0.0020 & 0.05 & 0.46 & 0.64 & & & & & & \\
\hline Adipose depots & 0.938 & $<0.0001$ & 0.029 & -0.07 & -2.42 & 0.017 & & & & & & \\
\hline Primates & $\mathbf{N}=\mathbf{2 3}$ & & & & & & & & & & & \\
\hline Heart & 0.347 & 1.00 & 0.033 & 0.65 & 2.99 & 0.007 & & & & & & \\
\hline Lungs & 0.703 & 0.13 & 0.25 & 0.44 & 1.93 & 0.07 & 0.44 & 1.97 & 0.06 & 0.51 & 1.97 & 0.06 \\
\hline Kidneys & 0.717 & 0.05 & 0.69 & 0.34 & 1.86 & 0.08 & 0.24 & 1.27 & 0.22 & 0.31 & 1.46 & 0.16 \\
\hline Liver & 0.664 & 0.18 & 0.16 & 0.20 & 1.06 & 0.30 & 0.14 & 0.73 & 0.48 & 0.27 & 1.29 & 0.21 \\
\hline Digestive tract & 1.000 & 0.10 & 1.00 & 0.48 & 3.14 & 0.005 & & & & 0.5 & 2.79 & 0.011 \\
\hline Stomach & 0.857 & 0.07 & 0.57 & 0.17 & 1.35 & 0.19 & 0.22 & 1.71 & 0.10 & 0.14 & 1.03 & 0.31 \\
\hline Intestine & 1.000 & 0.10 & 1.00 & 0.41 & 2.95 & 0.008 & & & & 0.41 & 2.57 & 0.018 \\
\hline Spleen & 0.838 & 0.036 & 0.29 & 0.15 & 1.56 & 0.13 & & & & & & \\
\hline Visceral organs & 0.663 & 0.17 & 0.31 & 0.50 & 2.35 & 0.029 & 0.51 & 2.43 & 0.025 & 0.57 & 2.46 & 0.023 \\
\hline Adipose depots & 0.793 & 0.29 & 0.23 & -0.01 & -0.10 & 0.92 & -0.02 & -0.26 & 0.80 & -0.09 & -1.11 & 0.28 \\
\hline Carnivora & $\mathbf{N}=\mathbf{2 8}$ & & & & & & & & & & & \\
\hline Heart & 0.000 & 1.00 & 0.0001 & -0.02 & -0.12 & 0.91 & & & & & & \\
\hline Lungs & 0.000 & 1.00 & 0.003 & -0.16 & -1.05 & 0.31 & & & & & & \\
\hline Kidneys & 0.000 & 1.00 & 0.001 & 0.050 & 0.33 & 0.74 & & & & & & \\
\hline Liver & 0.000 & 1.00 & 0.0003 & -0.01 & -0.08 & 0.93 & & & & & & \\
\hline Digestive tract & 0.000 & 1.00 & 0.0004 & 0.16 & 0.86 & 0.40 & & & & & & \\
\hline Stomach & 0.000 & 1.00 & 0.0002 & 0.08 & 0.55 & 0.59 & & & & & & \\
\hline Intestine & 0.000 & 1.00 & 0.0004 & 0.15 & 0.90 & 0.38 & & & & & & \\
\hline Spleen & 0.000 & 1.00 & 0.001 & -0.03 & -0.52 & 0.61 & & & & & & \\
\hline Visceral organs & 0.000 & 1.00 & 0.0003 & -0.09 & -0.41 & 0.69 & & & & & & \\
\hline Adipose depots & 0.000 & 1.00 & $<0.0001$ & -0.04 & -0.90 & 0.38 & & & & & & \\
\hline Rodentia & $\mathbf{N}=\mathbf{2 9}$ & & & & & & & & & & & \\
\hline Heart & 0.762 & 0.0004 & 0.001 & 0.23 & 1.90 & 0.07 & & & & & & \\
\hline Lungs & 0.788 & 0.0002 & 0.003 & -0.02 & -0.16 & 0.87 & & & & & & \\
\hline Kidneys & 0.776 & 0.0004 & 0.001 & -0.13 & -0.78 & 0.44 & & & & & & \\
\hline Liver & 0.784 & 0.0002 & 0.002 & -0.10 & -0.70 & 0.49 & & & & & & \\
\hline Digestive tract & 0.774 & 0.0038 & 0.0036 & -0.03 & -0.18 & 0.86 & & & & & & \\
\hline Stomach & 0.805 & 0.0007 & 0.014 & 0.05 & 0.34 & 0.74 & & & & & & \\
\hline Intestine & 0.769 & 0.003 & 0.002 & -0.04 & -0.29 & 0.78 & & & & & & \\
\hline Spleen & 0.825 & $<0.0001$ & 0.008 & -0.08 & -1.43 & 0.16 & & & & & & \\
\hline Visceral organs & 0.773 & 0.0007 & 0.001 & -0.10 & -0.48 & 0.63 & & & & & & \\
\hline Adipose depots & 0.821 & $<0.0001$ & 0.010 & -0.08 & -1.97 & 0.06 & & & & & & \\
\hline
\end{tabular}




\section{Supplementary Table 4 continued:}

\begin{tabular}{|c|c|c|c|c|c|c|c|c|c|c|c|c|}
\hline \multirow{3}{*}{$\begin{array}{c}\text { b) } \\
\text { Organ }\end{array}$} & \multicolumn{12}{|c|}{ Including whole body mass as covariate } \\
\hline & \multicolumn{6}{|c|}{ PGLS } & \multicolumn{3}{|c|}{$\begin{array}{c}\text { Independent contrasts } \\
(\lambda=1)\end{array}$} & \multicolumn{3}{|c|}{$\begin{array}{c}\text { Raw data } \\
(\lambda=0)\end{array}$} \\
\hline & $\lambda$ & $\mathrm{P}(\lambda=0)$ & $\mathrm{P}(\lambda=1)$ & $\beta$ & t-value & p-value & $\beta$ & t-value & p-value & $\beta$ & t-value & p-value \\
\hline Mammals & $\mathrm{N}=\mathbf{1 0 0}$ & & & & & & & & & & & \\
\hline Heart & 0.905 & $<0.0001$ & 0.0002 & 0.22 & 2.32 & 0.022 & & & & & & \\
\hline Lungs & 0.902 & $<0.0001$ & 0.0005 & 0.07 & 0.67 & 0.50 & & & & & & \\
\hline Kidneys & 0.901 & $<0.0001$ & 0.0003 & 0.09 & 0.87 & 0.38 & & & & & & \\
\hline Liver & 0.907 & $<0.0001$ & 0.0005 & 0.04 & 0.47 & 0.64 & & & & & & \\
\hline Digestive tract & 0.940 & $<0.0001$ & 0.003 & 0.22 & 2.70 & 0.008 & & & & & & \\
\hline Stomach & 0.928 & $<0.0001$ & 0.002 & 0.19 & 2.59 & 0.011 & & & & & & \\
\hline Intestine & 0.938 & $<0.0001$ & 0.003 & 0.16 & 2.31 & 0.023 & & & & & & \\
\hline Spleen & 0.912 & $<0.0001$ & 0.0010 & -0.01 & -0.29 & 0.77 & & & & & & \\
\hline Visceral organs & 0.909 & $<0.0001$ & 0.0002 & 0.16 & 1.42 & 0.16 & & & & & & \\
\hline Adipose depots & 0.932 & $<0.0001$ & 0.024 & -0.12 & -4.00 & 0.0001 & & & & & & \\
\hline Primates & $\mathbf{N}=\mathbf{2 3}$ & & & & & & & & & & & \\
\hline Heart & 0.445 & 0.74 & 0.036 & 0.63 & 3.18 & 0.005 & & & & & & \\
\hline Lungs & 0.759 & 0.10 & 0.28 & 0.45 & 2.01 & 0.06 & 0.60 & 2.31 & 0.032 & 0.47 & 2.16 & 0.043 \\
\hline Kidneys & 0.756 & 0.028 & 0.070 & 0.34 & 1.75 & 0.10 & & & & & & \\
\hline Liver & 0.737 & 0.09 & 0.14 & 0.21 & 1.12 & 0.28 & 0.17 & 0.91 & 0.38 & 0.33 & 1.52 & 0.14 \\
\hline Digestive tract & 1.000 & 0.07 & 1.00 & 0.49 & 3.30 & 0.004 & & & & 0.55 & 3.06 & 0.006 \\
\hline Stomach & 0.887 & 0.033 & 0.53 & 0.17 & 1.28 & 0.21 & & & & & & \\
\hline Intestine & 1.000 & 0.06 & 1.00 & 0.42 & 3.22 & 0.004 & & & & 0.45 & 2.92 & 0.009 \\
\hline Spleen & 0.775 & 0.009 & 0.36 & 0.18 & 1.95 & 0.07 & & & & & & \\
\hline Visceral organs & 0.734 & 0.12 & 0.34 & 0.51 & 2.44 & 0.024 & 0.53 & 2.62 & 0.016 & 0.63 & 2.77 & 0.012 \\
\hline Adipose depots & 0.781 & 0.26 & 0.21 & -0.07 & -0.91 & 0.37 & -0.06 & -1.01 & 0.32 & -0.15 & -1.87 & 0.08 \\
\hline Carnivora & $\mathrm{N}=\mathbf{2 8}$ & & & & & & & & & & & \\
\hline Heart & 0.000 & 1.00 & 0.0001 & 0.06 & 0.41 & 0.69 & & & & & & \\
\hline Lungs & 0.000 & 1.00 & 0.001 & -0.03 & -0.17 & 0.86 & & & & & & \\
\hline Kidneys & 0.000 & 1.00 & 0.0002 & 0.14 & 0.91 & 0.37 & & & & & & \\
\hline Liver & 0.000 & 1.00 & 0.0002 & 0.07 & 0.63 & 0.53 & & & & & & \\
\hline Digestive tract & 0.000 & 1.00 & 0.0006 & 0.28 & 1.58 & 0.13 & & & & & & \\
\hline Stomach & 0.000 & 1.00 & 0.0004 & 0.15 & 0.96 & 0.35 & & & & & & \\
\hline Intestine & 0.000 & 1.00 & 0.0006 & 0.26 & 1.66 & 0.11 & & & & & & \\
\hline Spleen & 0.000 & 1.00 & 0.003 & -0.03 & -0.55 & 0.59 & & & & & & \\
\hline Visceral organs & 0.000 & 1.00 & 0.0001 & 0.13 & 0.63 & 0.53 & & & & & & \\
\hline Adipose depots & 0.000 & 1.00 & $<0.0001$ & -0.11 & -2.09 & 0.047 & & & & & & \\
\hline Rodentia & $\mathrm{N}=\mathbf{2 9}$ & & & & & & & & & & & \\
\hline Heart & 0.732 & 0.001 & 0.0008 & 0.28 & 2.31 & 0.029 & & & & & & \\
\hline Lungs & 0.754 & 0.0006 & 0.0006 & 0.05 & 0.35 & 0.73 & & & & & & \\
\hline Kidneys & 0.754 & 0.0009 & 0.0006 & -0.03 & -0.17 & 0.86 & & & & & & \\
\hline Liver & 0.755 & 0.0007 & 0.0008 & -0.07 & -0.43 & 0.66 & & & & & & \\
\hline Digestive tract & 0.792 & 0.002 & 0.005 & 0.08 & 0.51 & 0.61 & & & & & & \\
\hline Stomach & 0.809 & 0.001 & 0.026 & 0.11 & 0.74 & 0.46 & & & & & & \\
\hline Intestine & 0.779 & 0.002 & 0.002 & 0.05 & 0.35 & 0.73 & & & & & & \\
\hline Spleen & 0.804 & 0.0001 & 0.003 & -0.08 & -1.37 & 0.18 & & & & & & \\
\hline Visceral organs & 0.762 & 0.0009 & 0.0006 & 0.03 & 0.12 & 0.90 & & & & & & \\
\hline Adipose depots & 0.800 & $<0.0001$ & 0.007 & -0.11 & -2.67 & 0.013 & & & & & & \\
\hline
\end{tabular}


Supplementary Table 5: Pair-wise phylogenetic least-squares regression (PGLS) between brain and other organ masses ( $\mathrm{N}=45$ species), controlling for a) fat-free body mass, and $\mathrm{b}$ ) whole body mass.

\begin{tabular}{|c|c|c|c|c|c|c|}
\hline \multirow[b]{2}{*}{ Organ } & \multicolumn{6}{|c|}{ Including fat-free body mass as covariate } \\
\hline & $\lambda$ & $\mathrm{P}(\lambda=0)$ & $\mathrm{P}(\lambda=1)$ & $\beta$ & t-value & p-value \\
\hline Mammals & $\mathrm{N}=45$ & & & & & \\
\hline Heart & 0.933 & $<0.0001$ & 0.05 & 0.18 & 1.06 & 0.29 \\
\hline Lungs & 0.918 & $<0.0001$ & 0.024 & 0.003 & 0.02 & 0.99 \\
\hline Kidneys & 0.917 & $<0.0001$ & 0.02 & 0.05 & 0.30 & 0.77 \\
\hline Liver & 0.919 & $<0.0001$ & 0.019 & 0.05 & 0.37 & 0.71 \\
\hline Digestive tract & 0.933 & $<0.0001$ & 0.08 & 0.11 & 0.74 & 0.46 \\
\hline Stomach & 0.936 & $<0.0001$ & 0.10 & 0.16 & 0.99 & 0.33 \\
\hline Intestine & 0.928 & $<0.0001$ & 0.049 & 0.07 & 0.53 & 0.60 \\
\hline Spleen & 0.933 & $<0.0001$ & 0.06 & -0.04 & -0.92 & 0.36 \\
\hline Visceral organs & 0.924 & $<0.0001$ & 0.024 & 0.12 & 0.58 & 0.57 \\
\hline Adipose depots & 0.940 & $<0.0001$ & 0.14 & -0.13 & -3.52 & 0.001 \\
\hline Non-Rodentia & $\mathrm{N}=\mathbf{2 1}$ & & & & & \\
\hline Heart & 0.987 & 0.001 & 0.86 & 0.04 & 0.14 & 0.89 \\
\hline Lungs & 0.999 & 0.001 & 0.99 & 0.14 & 0.55 & 0.59 \\
\hline Kidneys & 1.000 & 0.0006 & 1.00 & 0.32 & 1.12 & 0.28 \\
\hline Liver & 1.000 & 0.0005 & 1.00 & 0.20 & 1.33 & 0.20 \\
\hline Digestive tract & 0.981 & 0.002 & 0.80 & -0.02 & -0.09 & 0.93 \\
\hline Stomach & 0.981 & 0.002 & 0.81 & 0.01 & 0.06 & 0.96 \\
\hline Intestine & 0.981 & 0.002 & 0.80 & -0.04 & -0.14 & 0.89 \\
\hline Spleen & 0.981 & 0.002 & 0.80 & 0.009 & 0.15 & 0.88 \\
\hline Visceral organs & 1.000 & 0.0008 & 1.00 & 0.35 & 1.18 & 0.25 \\
\hline Adipose depots & 0.917 & 0.0004 & 0.30 & -0.18 & -2.66 & 0.016 \\
\hline Rodentia & $\mathrm{N}=\mathbf{2 4}$ & & & & & \\
\hline Heart & 0.646 & 0.07 & 0.001 & 0.53 & 2.65 & 0.015 \\
\hline Lungs & 0.762 & 0.002 & 0.004 & 0.01 & 0.07 & 0.94 \\
\hline Kidneys & 0.755 & 0.003 & 0.002 & -0.12 & -0.62 & 0.54 \\
\hline Liver & 0.764 & 0.002 & 0.004 & -0.11 & -0.63 & 0.53 \\
\hline Digestive tract & 0.799 & 0.006 & 0.023 & 0.08 & 0.43 & 0.67 \\
\hline Stomach & 0.816 & 0.004 & 0.049 & 0.13 & 0.65 & 0.52 \\
\hline Intestine & 0.783 & 0.005 & 0.01 & 0.04 & 0.25 & 0.80 \\
\hline Spleen & 0.826 & 0.0003 & 0.023 & -0.09 & -1.47 & 0.16 \\
\hline Visceral organs & 0.758 & 0.003 & 0.002 & -0.05 & -0.20 & 0.84 \\
\hline Adipose depots & 0.829 & 0.0002 & 0.031 & -0.09 & -2.15 & 0.043 \\
\hline
\end{tabular}




\section{Supplementary Table 5 continued:}

\begin{tabular}{|c|c|c|c|c|c|c|}
\hline \multirow[b]{2}{*}{ Organ } & \multicolumn{6}{|c|}{ Including whole body mass as covariate } \\
\hline & $\lambda$ & $\mathrm{P}(\lambda=0)$ & $\mathrm{P}(\lambda=1)$ & $\beta$ & t-value & p-value \\
\hline Mammals & $\mathrm{N}=45$ & & & & & \\
\hline Heart & 0.942 & $<0.0001$ & 0.09 & 0.33 & 1.98 & 0.054 \\
\hline Lungs & 0.910 & $<0.0001$ & 0.009 & 0.15 & 0.89 & 0.38 \\
\hline Kidneys & 0.906 & $<0.0001$ & 0.015 & 0.20 & 1.17 & 0.25 \\
\hline Liver & 0.912 & $<0.0001$ & 0.01 & 0.12 & 0.93 & 0.36 \\
\hline Digestive tract & 0.945 & $<0.0001$ & 0.14 & 0.25 & 1.72 & 0.09 \\
\hline Stomach & 0.949 & $<0.0001$ & 0.22 & 0.32 & 2 & 0.05 \\
\hline Intestine & 0.935 & $<0.0001$ & 0.07 & 0.17 & 1.36 & 0.18 \\
\hline Spleen & 0.923 & $<0.0001$ & 0.035 & -0.04 & -0.77 & 0.45 \\
\hline Visceral organs & 0.928 & $<0.0001$ & 0.022 & 0.33 & 1.64 & 0.11 \\
\hline Adipose depots & 0.929 & $<0.0001$ & 0.11 & -0.18 & -4.46 & $<0.0001$ \\
\hline Non-Rodentia & $\mathbf{N}=\mathbf{2 1}$ & & & & & \\
\hline Heart & 1.000 & 0.002 & 1.00 & 0.25 & 0.94 & 0.36 \\
\hline Lungs & 1.000 & 0.001 & 1.00 & 0.34 & 1.26 & 0.22 \\
\hline Kidneys & 1.000 & 0.0006 & 1.00 & 0.53 & 1.77 & 0.09 \\
\hline Liver & 1.000 & 0.0006 & 1.00 & 0.26 & 1.70 & 0.11 \\
\hline Digestive tract & 0.993 & 0.003 & 0.94 & 0.16 & 0.6 & 0.56 \\
\hline Stomach & 0.990 & 0.003 & 0.91 & 0.21 & 0.83 & 0.41 \\
\hline Intestine & 0.991 & 0.003 & 0.92 & 0.10 & 0.44 & 0.66 \\
\hline Spleen & 0.991 & 0.003 & 0.92 & 0.02 & 0.26 & 0.80 \\
\hline Visceral organs & 1.000 & 0.0004 & 1.00 & 0.56 & 1.95 & 0.07 \\
\hline Adipose depots & 0.891 & 0.0006 & 0.19 & -0.27 & -3.68 & 0.002 \\
\hline Rodentia & $N=24$ & & & & & \\
\hline Heart & 0.604 & 0.11 & 0.001 & 0.60 & 3.14 & 0.005 \\
\hline Lungs & 0.712 & 0.007 & 0.001 & 0.12 & 0.59 & 0.56 \\
\hline Kidneys & 0.727 & 0.005 & 0.001 & -0.008 & -0.04 & 0.97 \\
\hline Liver & 0.725 & 0.005 & 0.002 & -0.06 & -0.30 & 0.76 \\
\hline Digestive tract & 0.825 & 0.004 & 0.036 & 0.20 & 1.14 & 0.27 \\
\hline Stomach & 0.845 & 0.004 & 0.12 & 0.27 & 1.26 & 0.22 \\
\hline Intestine & 0.796 & 0.004 & 0.012 & 0.13 & 0.86 & 0.40 \\
\hline Spleen & 0.800 & 0.001 & 0.011 & -0.10 & -1.45 & 0.16 \\
\hline Visceral organs & 0.746 & 0.004 & 0.002 & 0.10 & 0.41 & 0.69 \\
\hline Adipose depots & 0.810 & 0.0004 & 0.023 & 0.80 & 13.65 & $<0.0001$ \\
\hline
\end{tabular}




\subsection{Dataset composition}

This section contains a description of the composition of the dataset (Suppl. Table 6), and additional results of a procedure to control for a potential bias in the sample (Suppl. Table 7).

The composition of our dataset in relation to the total existing numbers of mammal species and families is shown in Suppl. Table 6. Although our dataset covers less than $2 \%$ of all mammal species, about a quarter of all mammal families are represented in our sample. However, Carnivora and Primates are overrepresented at the species level in our sample, whereas many small orders are not covered.

Supplementary Table 6: Composition of the organ mass sample. Numbers of mammalian species are taken from Wilson and Reeder ${ }^{49}$.

\begin{tabular}{l|ccc|ccc} 
& Species & & Families & & \\
\hline & All & in our sample & coverage [\%] & All & in our sample & coverage [\%] \\
\hline Marsupialia & & & & & & \\
Didelphimorphia & 87 & 1 & 1.1 & 1 & 1 & 100.0 \\
$\begin{array}{l}\text { Diprotodontia } \\
\text { other marsupials }\end{array}$ & 143 & 3 & 2.1 & 11 & 3 & 27.3 \\
& 101 & 0 & 0 & 9 & 0 & 0 \\
Monotremata & 5 & 0 & 0 & 2 & 0 & 0 \\
& & & & & & \\
Placentalia & & & & & & \\
Artiodactyla & 240 & 3 & 1.3 & 10 & 3 & 60.0 \\
Carnivora & 286 & 28 & 9.8 & 15 & 9 & 5.6 \\
Chiroptera & 1116 & 3 & 0.3 & 18 & 1 & 100.0 \\
Erinaceomorpha & 24 & 1 & 4.2 & 1 & 1 & 33.3 \\
Lagomorpha & 92 & 2 & 2.2 & 3 & 1 & 33.3 \\
Primates & 376 & 23 & 6.1 & 15 & 8 & 33.3 \\
Rodentia & 2277 & 29 & 1.3 & 33 & 11 & 50.0 \\
Scandentia & 20 & 1 & 5.0 & 2 & 1 & 0 \\
Sorcimorpha & 428 & 6 & 1.4 & 4 & 2 & 24.2 \\
other mammals & 221 & 0 & 0 & 29 & 0 & 30 \\
\hline Total & 5195 & 100 & 1.9 & 124 & & \\
\hline
\end{tabular}

While phylogenetic methods are quite suitable to accommodate grade shifts in the data, an imbalance in the sample in combination with a different relationship within a specious taxon from that in other taxa, may still affect the results. One option to control for a possible bias is to look at large groups separately, which we did in Suppl. Tables 4 and 5. In general, the correlations are retained within the large orders, with the exception of primates (see Section 3.6). 
Another option is to resample a better-balanced subset of the data, accepting the reduced sample size. We did this by selecting one species from each subfamily according to data quality (sample size, wild $>$ captive, females $>$ males, total adipose depots measured). Our final sample included 51 species. The significantly negative correlation between brain size and adipose depots mass persists in this subsample, although the p-value is slightly higher (Suppl. Table 7).

Supplementary Table 7: Pair-wise phylogenetic least-squares regression (PGLS) between brain and other organ masses $(\mathrm{N}=51$ species, one per subfamily), controlling for fat-free body mass.

\begin{tabular}{|l|cccccc|}
\hline \multicolumn{1}{|c|}{ Organ } & $\lambda$ & $\mathrm{P}(\lambda=0)$ & $\mathrm{P}(\lambda=1)$ & $\beta$ & t-value & $\mathrm{p}$-value \\
\hline Heart & 0.936 & $<0.0001$ & 0.46 & 0.08 & 0.59 & 0.56 \\
Lungs & 0.929 & $<0.0001$ & 0.42 & 0.02 & 0.13 & 0.90 \\
Kidneys & 0.959 & $<0.0001$ & 0.56 & 0.25 & 1.69 & 0.10 \\
Liver & 0.943 & $<0.0001$ & 0.51 & 0.07 & 0.56 & 0.58 \\
Digestive tract & 0.929 & $<0.0001$ & 0.42 & 0.01 & 0.06 & 0.95 \\
$\quad$ Stomach & 0.933 & $<0.0001$ & 0.45 & -0.05 & -0.42 & 0.68 \\
$\quad$ Intestine & 0.941 & $<0.0001$ & 0.51 & 0.05 & 0.44 & 0.66 \\
Spleen & 0.920 & $<0.0001$ & 0.38 & -0.03 & -0.42 & 0.68 \\
Visceral organs & 0.941 & $<0.0001$ & 0.51 & 0.08 & 0.42 & 0.68 \\
Adipose depots & 0.904 & $<0.0001$ & 0.24 & -0.10 & -2.06 & $\mathbf{0 . 0 4 5}$ \\
\hline
\end{tabular}




\subsection{An alternative method to estimate total adipose depots mass}

This section contains additional results on the relationship between brain size and adipose depots mass using an alternative method to estimate total adipose depots mass from abdominal depots mass (Suppl. Figure 4 and Suppl. Table 8).

As the variation in abdominal and total mass of adipose depots is rather large (cf. Suppl. Figure 1), we applied an alternative method to scale abdominal adipose depots to total adipose depots using the correlation between the two variables in 9 specimens for which we have both measurements (Rattus norvegicus, two Mus musculus, Glis glis, Martes foina, Mephitis mephitis, Vulpes vulpes, Saimiri sciureus and Macaca fuscata). A least-squares regression (Suppl. Figure 4) yields the following prediction equation:

$\ln ($ total adipose depots $)=0.564+1.047 * \ln ($ abdominal adipose depots $)$

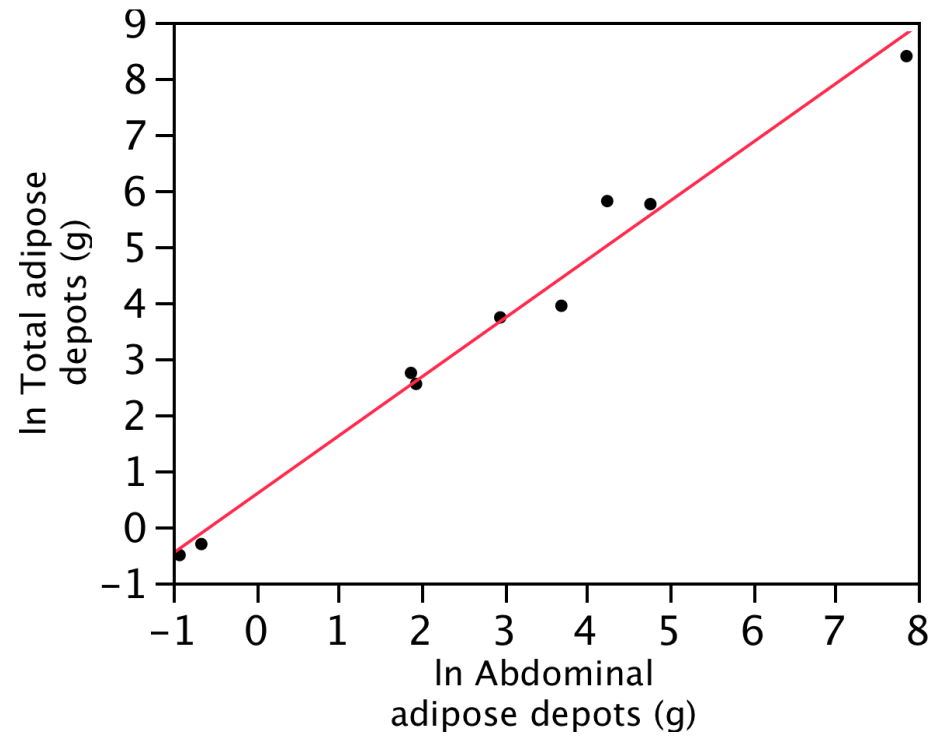

Supplementary Figure 4: Regression of abdominal adipose depots vs. total adipose depots $\left(\mathrm{N}=9, \mathrm{r}^{2}=0.982, \mathrm{P}<0.0001\right)$.

From this, total adipose depots mass was calculated for all specimens for which only abdominal adipose depots mass was available. The resulting negative correlations between brain size and adipose depots mass are slightly stronger in all groups, most notably in all mammals combined (Suppl. Table 8). This result suggests that the found brain size - adipose depot tradeoff is robust and does not rely on the details of the method used to scale the abdominal to total adipose depots mass. 
Supplementary Table 8: Pair-wise phylogenetic least-squares regression (PGLS) between brain size and adipose depots mass, controlling for fat-free body mass, using an alternative method to calculate total adipose depots mass. Original results are duplicated from Suppl. Table 4a).

\begin{tabular}{|cc|c|cccccc|}
\hline & & $\mathrm{N}$ & $\lambda$ & $\mathrm{P}(\lambda=0)$ & $\mathrm{P}(\lambda=1)$ & $\beta$ & t-value & $\mathrm{p}$-value \\
\hline \multirow{2}{*}{ All } & Original & 100 & 0.938 & $<0.0001$ & 0.029 & -0.07 & -2.42 & $\mathbf{0 . 0 1 7}$ \\
mammals & Alternative & 100 & 0.927 & $<0.0001$ & 0.003 & -0.09 & -2.07 & $\mathbf{0 . 0 0 2}$ \\
\hline \multirow{2}{*}{ Primates } & Original & 23 & 0.793 & 0.29 & 0.23 & -0.01 & -0.10 & 0.92 \\
& Alternative & 23 & 0.787 & 0.29 & 0.22 & -0.03 & -0.41 & 0.69 \\
\hline \multirow{2}{*}{ Carnivora } & Original & 28 & 0.000 & 1.00 & $<0.0001$ & -0.04 & -0.90 & 0.38 \\
& Alternative & 28 & 0.000 & 1.00 & 0.001 & -0.07 & -1.48 & 0.15 \\
\hline \multirow{2}{*}{ Rodentia } & Original & 29 & 0.821 & $<0.0001$ & 0.010 & -0.08 & -1.97 & 0.06 \\
& Alternative & 29 & 0.822 & $<0.0001$ & 0.010 & -0.08 & -2.02 & 0.054 \\
\hline
\end{tabular}

\subsection{Reducing error variation by splitting the sample into wild/captive, and male/female subsamples}

This section contains additional results produced when the dataset was split into subsamples in an attempt to reduce error variation in the relationship between brain size and adipose depots mass (Suppl. Table 9).

Our organ mass sample contains specimens from a variety of living conditions, of both sexes, and from various habitats (cf. Suppl. Data), which may induce a large amount of error variation. By splitting our sample into subsets according to these groups, we can investigate whether the negative correlation between brain size and adipose depots mass is robust. We expect that the trade-off between fat storage and brain size is more pronounced in females than in males, because the former are more affected by energy constraints due to offspring production. As captivity effects are rather unpredictable (most animals gain weight in captivity, but only under good husbandry conditions), we expect that the trade-off is more pronounced in wild-caught specimens, although it may be argued that they are also more affected by seasonality effects on fat storage. Finally, storing fat may only be beneficial for survival if food availability in the habitat is seasonally variable. We therefore expect the trade-off to be more pronounced in species originating from temperate rather than from tropical habitats.

Results, shown in Suppl. Table 9, fully confirm these predictions. A significant negative correlation between brain size and adipose depots mass, controlling for fat-free body mass, is found in females, in wild-caught specimens, and in species of temperate origin, and is most pronounced in the subset of wild females. This result suggests that reducing error variation and 
controlling for potentially confounding variables strengthens the evidence for a brain sizeadipose depot trade-off.

Supplementary Table 9: Pair-wise phylogenetic least-squares regression (PGLS) between brain size and adipose depots mass split by habitat (temperate, tropical, both), sex (male, female), and provenience (captive, wild, no data), controlling for fat-free body mass. a) $\mathrm{N}=100$ species, b) $\mathrm{N}=45$ species.

a)

\begin{tabular}{|c|c|cccccc|}
\hline Group & $\mathrm{N}$ & $\lambda$ & $\mathrm{P}(\lambda=0)$ & $\mathrm{P}(\lambda=1)$ & $\beta$ & $\mathrm{t}$-value & $\mathrm{p}$-value \\
\hline All specimens & 100 & 0.938 & $<0.0001$ & 0.029 & -0.07 & -2.42 & $\mathbf{0 . 0 1 7}$ \\
\hline Temperate & 52 & 0.933 & $<0.0001$ & 0.12 & -0.08 & -2.07 & $\mathbf{0 . 0 4 3}$ \\
Tropical & 43 & 0.934 & $<0.0001$ & 0.23 & -0.01 & -0.24 & 0.81 \\
\hline Females & 57 & 0.934 & $<0.0001$ & 0.006 & -0.09 & -2.45 & $\mathbf{0 . 0 1 7}$ \\
Males & 69 & 0.905 & $<0.0001$ & 0.006 & -0.06 & -1.68 & 0.10 \\
\hline Wild & 39 & 0.964 & $<0.0001$ & 0.39 & -0.12 & -2.74 & $\mathbf{0 . 0 1 0}$ \\
Captive & 59 & 0.823 & $<0.0001$ & 0.019 & -0.03 & -0.77 & 0.44 \\
Wild females & 28 & 1.000 & 0.0004 & 1.00 & -0.12 & -3.42 & $\mathbf{0 . 0 0 2}$ \\
\hline
\end{tabular}

b)

\begin{tabular}{|c|c|c|c|c|c|c|c|}
\hline & $\mathrm{N}$ & $\lambda$ & $\mathrm{P}(\lambda=0)$ & $P(\lambda=1)$ & $\beta$ & t-value & $\mathrm{p}$-value \\
\hline All specimens & 45 & 0.940 & $<0.0001$ & 0.14 & -0.13 & -3.52 & 0.001 \\
\hline $\begin{array}{c}\text { Temperate } \\
\text { Tropical }\end{array}$ & $\begin{array}{c}39 \\
4 \\
\end{array}$ & 0.951 & $<0.0001$ & 0.24 & -0.1 & -2.37 & 0.023 \\
\hline Females & 30 & 1.000 & $<0.0001$ & 1.00 & -0.12 & -4.27 & 0.0002 \\
\hline Males & 33 & 0.876 & 0.0002 & 0.006 & -0.12 & -2.13 & 0.041 \\
\hline Wild & 35 & 0.951 & $<0.0001$ & 0.31 & -0.14 & -2.78 & 0.009 \\
\hline Captive & 8 & 0.000 & 1.00 & 0.019 & 0.02 & 0.26 & 0.81 \\
\hline Wild females & 25 & 1.000 & 0.0004 & 1.00 & -0.13 & -3.68 & 0.0013 \\
\hline
\end{tabular}




\subsection{Potential autocorrelation effects and compositional data analysis}

This section contains results of an alternative procedure to control for the effect of body size (Suppl. Tables 10 and 11), and the results of compositional data analysis for the relationship between adipose depots mass and brain size (Suppl. Table 12).

A potential problem in the analysis of body composition data is the presence of autocorrelation effects, as the organs are part of the body mass which is used to control for size effects $^{50}$. These effects are most pronounced when the parts comprise a large proportion of the whole body, but this is not the case in most of the correlations between brain size and one of the visceral organs in our sample. Furthermore, autocorrelation assumes that the total size of a sum of variables is strictly limited and thus constant. In the case of body mass, this assumption is overly conservative, because adding the size of some organ does not need to constrain the size of other organs. Nevertheless, to validate our results we applied two procedures to control for potential autocorrelation effects.

First, if we adjust our estimate of body size by controlling for fat-free body mass minus brain mass and the respective organ mass instead of just fat-free body mass, p-values remain largely similar, and in no case is the level of significance affected (Suppl. Table 10). The most critical result is the negative correlation between brain size and adipose depots mass. We checked for autocorrelation effects by controlling for fat-free body mass minus brain mass (Suppl. Table 11, analogous to the procedure for visceral organs shown in Suppl. Table 10). Results remain unchanged in the $\mathrm{N}=100$ species sample, but significance is lost in the subsamples of the $\mathrm{N}=45$ species sample.

Second, we applied compositional data analysis to control for potential autocorrelation effects in the brain size vs. adipose depots mass correlation (Suppl. Table 12). This method was developed for mathematical geology ${ }^{51}$, and it has been applied to intraspecific body composition data before ${ }^{52}$. It takes into account that $n$ parts of a whole are by necessity autocorrelated and transforms the values by projecting them onto a simplex of $n-1$ dimensions. We used the function acomp for closed compositions in a logistic geometry, following a log-ratio approach and the isometric log-ratio transform $i l r^{53}$ from the package compositions ${ }^{54}$ in $\mathrm{R}^{35}$. Thus, from the raw values of brain mass, adipose depots mass and the remaining body mass without brain and adipose depots, we obtained two transformed variables, which are no longer autocorrelated. We then tested their correlation with phylogenetic regression using pglmEstLambda from the package CAIC in R. Results yield very strong negative correlations in all subsamples. 
Supplementary Table 10: Pair-wise phylogenetic least-squares regression (PGLS) between brain size and the mass of visceral organs, controlling for fat-free body mass minus brain mass and the respective organ mass. a) $\mathrm{N}=100$ species, b) $\mathrm{N}=45$ species.

\begin{tabular}{|c|c|c|c|c|c|c|c|c|c|c|c|c|}
\hline \multirow{3}{*}{$\begin{array}{c}\text { a) } \\
\text { Organ }\end{array}$} & \multicolumn{12}{|c|}{ Including fat-free body mass minus brain mass and organ mass as covariate } \\
\hline & \multicolumn{6}{|c|}{ PGLS } & \multicolumn{3}{|c|}{$\begin{array}{c}\text { Independent contrasts } \\
(\lambda=1)\end{array}$} & \multicolumn{3}{|c|}{$\begin{array}{c}\text { Raw data } \\
(\lambda=0)\end{array}$} \\
\hline & $\lambda$ & $\mathrm{P}(\lambda=0)$ & $\mathrm{P}(\lambda=1)$ & $\beta$ & t-value & p-value & $\beta$ & t-value & p-value & $\beta$ & t-value & p-value \\
\hline Mammals & $\mathbf{N}=\mathbf{1 0 0}$ & & & & & & & & & & & \\
\hline Heart & 0.918 & $<0.0001$ & 0.001 & 0.16 & 1.70 & 0.09 & & & & & & \\
\hline Lungs & 0.926 & $<0.0001$ & 0.009 & -0.01 & -0.08 & 0.93 & & & & & & \\
\hline Kidneys & 0.921 & $<0.0001$ & 0.004 & 0.03 & 0.30 & 0.77 & & & & & & \\
\hline Liver & 0.923 & $<0.0001$ & 0.004 & 0.02 & 0.30 & 0.77 & & & & & & \\
\hline Digestive tract & 0.945 & $<0.0001$ & 0.008 & 0.19 & 2.28 & 0.025 & & & & & & \\
\hline Stomach & 0.936 & $<0.0001$ & 0.006 & 0.16 & 2.27 & 0.026 & & & & & & \\
\hline Intestine & 0.942 & $<0.0001$ & 0.007 & 0.13 & 1.77 & 0.08 & & & & & & \\
\hline Spleen & 0.929 & $<0.0001$ & 0.008 & -0.02 & -0.44 & 0.66 & & & & & & \\
\hline Visc. organs & 0.923 & $<0.0001$ & 0.002 & 0.14 & 1.35 & 0.18 & & & & & & \\
\hline Primates & $\mathbf{N}=\mathbf{2 3}$ & & & & & & & & & & & \\
\hline Heart & 0.325 & 1.00 & 0.032 & 0.68 & 3.12 & 0.005 & & & & & & \\
\hline Lungs & 0.702 & 0.13 & 0.28 & 0.47 & 2.07 & 0.05 & 0.46 & 2.09 & 0.050 & 0.54 & 2.12 & 0.047 \\
\hline Kidneys & 0.719 & 0.0495 & 0.07 & 0.35 & 1.94 & 0.07 & & & & & & \\
\hline Liver & 0.670 & 0.17 & 0.17 & 0.24 & 1.27 & 0.22 & 0.17 & 0.91 & 0.38 & 0.31 & 1.50 & 0.15 \\
\hline Digestive tract & 1.000 & 0.10 & 1.00 & 0.49 & 3.32 & 0.003 & & & & 0.53 & 3.01 & 0.007 \\
\hline Stomach & 0.882 & 0.07 & 0.66 & 0.18 & 1.47 & 0.16 & 0.23 & 1.80 & 0.09 & 0.15 & 1.14 & 0.27 \\
\hline Intestine & 1.000 & 0.09 & 1.00 & 0.33 & 2.59 & 0.018 & & & & 0.44 & 2.76 & 0.012 \\
\hline Spleen & 0.845 & 0.034 & 0.31 & 0.16 & 1.61 & 0.12 & & & & & & \\
\hline Visc. organs & 0.674 & 0.16 & 0.35 & 0.54 & 2.80 & 0.011 & 0.54 & 2.79 & 0.011 & 0.61 & 2.91 & 0.009 \\
\hline Carnivora & $\mathrm{N}=\mathbf{2 8}$ & & & & & & & & & & & \\
\hline Heart & 0.000 & 1.00 & 0.0005 & 0.01 & 0.04 & 0.96 & & & & & & \\
\hline Lungs & 0.000 & 1.00 & 0.014 & -0.11 & -0.76 & 0.45 & & & & & & \\
\hline Kidneys & 0.000 & 1.00 & 0.007 & 0.080 & 0.55 & 0.59 & & & & & & \\
\hline Liver & 0.000 & 1.00 & 0.0010 & 0.03 & 0.27 & 0.79 & & & & & & \\
\hline Digestive tract & 0.000 & 1.00 & 0.0007 & 0.19 & 1.00 & 0.33 & & & & & & \\
\hline Stomach & 0.000 & 1.00 & 0.0009 & 0.09 & 0.58 & 0.57 & & & & & & \\
\hline Intestine & 0.000 & 1.00 & 0.0006 & 0.17 & 1.02 & 0.32 & & & & & & \\
\hline Spleen & 0.000 & 1.00 & 0.013 & -0.02 & -0.44 & 0.67 & & & & & & \\
\hline Visc. organs & 0.000 & 1.00 & 0.002 & 0.04 & 0.20 & 0.85 & & & & & & \\
\hline Rodentia & $\mathbf{N}=\mathbf{2 9}$ & & & & & & & & & & & \\
\hline Heart & 0.760 & 0.0005 & 0.001 & 0.24 & 2.00 & 0.06 & & & & & & \\
\hline Lungs & 0.786 & 0.0002 & 0.003 & -0.01 & -0.03 & 0.98 & & & & & & \\
\hline Kidneys & 0.775 & 0.0005 & 0.001 & -0.12 & -0.66 & 0.51 & & & & & & \\
\hline Liver & 0.783 & 0.0002 & 0.002 & -0.06 & -0.44 & 0.66 & & & & & & \\
\hline Digestive tract & 0.779 & 0.0030 & 0.004 & -0.02 & 0.11 & 0.91 & & & & & & \\
\hline Stomach & 0.808 & 0.0006 & 0.016 & 0.07 & 0.45 & 0.66 & & & & & & \\
\hline Intestine & 0.773 & 0.002 & 0.002 & -0.01 & -0.04 & 0.97 & & & & & & \\
\hline Spleen & 0.824 & $<0.0001$ & 0.007 & -0.08 & -1.39 & 0.18 & & & & & & \\
\hline Visc. organs & 0.774 & 0.0006 & 0.001 & 0.01 & 0.05 & 0.96 & & & & & & \\
\hline
\end{tabular}


Supplementary Table 10 continued:

\begin{tabular}{|c|c|c|c|c|c|c|}
\hline \multirow[b]{2}{*}{ Organ } & \multicolumn{6}{|c|}{ Including fat-free body mass minus brain mass and organ mass as covariate } \\
\hline & $\lambda$ & $\mathrm{P}(\lambda=0)$ & $\mathrm{P}(\lambda=1)$ & $\beta$ & t-value & p-value \\
\hline Mammals & $\mathrm{N}=45$ & & & & & \\
\hline Heart & 0.945 & $<0.0001$ & 0.10 & 0.20 & 1.23 & 0.22 \\
\hline Lungs & 0.930 & $<0.0001$ & 0.05 & 0.01 & 0.07 & 0.94 \\
\hline Kidneys & 0.930 & $<0.0001$ & 0.043 & 0.04 & 0.22 & 0.83 \\
\hline Liver & 0.930 & $<0.0001$ & 0.033 & 0.09 & 0.82 & 0.41 \\
\hline Digestive tract & 0.936 & $<0.0001$ & 0.08 & 0.07 & 0.45 & 0.66 \\
\hline Stomach & 0.949 & $<0.0001$ & 0.20 & 0.16 & 0.99 & 0.33 \\
\hline Intestine & 0.932 & $<0.0001$ & 0.05 & 0.03 & 0.19 & 0.85 \\
\hline Spleen & 0.939 & $<0.0001$ & 0.08 & -0.03 & -0.62 & 0.54 \\
\hline Visceral organs & 0.934 & $<0.0001$ & 0.041 & 0.17 & 0.98 & 0.33 \\
\hline Non-Rodentia & $\mathrm{N}=\mathbf{2 4}$ & & & & & \\
\hline Heart & 0.693 & 0.027 & 0.002 & 0.49 & 2.54 & 0.019 \\
\hline Lungs & 0.781 & 0.002 & 0.009 & 0.01 & 0.50 & 0.96 \\
\hline Kidneys & 0.768 & 0.002 & 0.003 & -0.14 & -0.72 & 0.48 \\
\hline Liver & 0.78 & 0.001 & 0.007 & -0.08 & -0.49 & 0.63 \\
\hline Digestive tract & 0.764 & 0.016 & 0.013 & -0.01 & -0.05 & 0.96 \\
\hline Stomach & 0.824 & 0.005 & 0.10 & 0.11 & 0.53 & 0.60 \\
\hline Intestine & 0.757 & 0.01 & 0.007 & -0.03 & -0.19 & 0.86 \\
\hline Spleen & 0.827 & 0.0003 & 0.021 & -0.08 & -1.15 & 0.26 \\
\hline Visceral organs & 0.768 & 0.003 & 0.004 & -0.02 & -0.10 & 0.92 \\
\hline Rodentia & $\mathbf{N}=\mathbf{2 1}$ & & & & & \\
\hline Heart & 0.984 & 0.001 & 0.85 & 0.08 & 0.30 & 0.77 \\
\hline Lungs & 0.995 & 0.001 & 0.95 & 0.15 & 0.57 & 0.57 \\
\hline Kidneys & 1.000 & 0.0009 & 0.99 & 0.26 & 0.92 & 0.37 \\
\hline Liver & 1.000 & 0.0004 & 1.00 & 0.25 & 1.77 & 0.09 \\
\hline Digestive tract & 0.971 & 0.002 & 0.71 & -0.03 & -0.13 & 0.90 \\
\hline Stomach & 0.974 & 0.001 & 0.74 & 0.002 & 0.006 & 0.99 \\
\hline Intestine & 0.971 & 0.002 & 0.71 & -0.04 & -0.19 & 0.85 \\
\hline Spleen & 0.972 & 0.001 & 0.72 & 0.02 & 0.26 & 0.80 \\
\hline Visceral organs & 1.000 & 0.0008 & 1.00 & 0.40 & 1.61 & 0.12 \\
\hline
\end{tabular}


Supplementary Table 11: Pair-wise phylogenetic least-squares regression (PGLS) between brain size and adipose depots mass, controlling for fat-free body mass minus brain mass. a) $\mathrm{N}=100$ species, b) $\mathrm{N}=45$ species.

\begin{tabular}{|c|c|c|c|c|c|c|c|c|c|c|c|c|c|}
\hline \multicolumn{2}{|l|}{ a) } & \multicolumn{6}{|c|}{ PGLS } & \multicolumn{3}{|c|}{$\begin{array}{c}\text { Independent contrasts } \\
(\lambda=1)\end{array}$} & \multicolumn{3}{|c|}{$\begin{array}{c}\text { Raw data } \\
(\lambda=0)\end{array}$} \\
\hline Group & $\mathrm{N}$ & $\lambda$ & $\mathrm{P}(\lambda=0)$ & $\mathrm{P}(\lambda=1)$ & $\beta$ & t-value & p-value & $\beta$ & t-value & p-value & $\beta$ & t-value & $\mathrm{p}$-value \\
\hline Mammals & 100 & 0.939 & $<0.0001$ & 0.03 & -0.07 & -2.39 & 0.019 & & & & & & \\
\hline Primates & 23 & 0.805 & 0.28 & 0.25 & -0.01 & -0.07 & 0.95 & -0.01 & -0.24 & 0.81 & -0.09 & -1.09 & 0.29 \\
\hline Carnivora & 28 & 0.000 & 1.00 & 0.011 & -0.05 & -1.02 & 0.32 & & & & & & \\
\hline Rodentia & 29 & 0.820 & $<0.0001$ & 0.010 & -0.08 & -1.95 & 0.06 & & & & & & \\
\hline
\end{tabular}

\begin{tabular}{|c|c|cccccc|}
\cline { 3 - 8 } \multicolumn{1}{c|}{ b) } & \multicolumn{7}{|c|}{ PGLS } \\
\hline Group & $\mathrm{N}$ & $\lambda$ & $\mathrm{P}(\lambda=0)$ & $\mathrm{P}(\lambda=1)$ & $\beta$ & t-value & p-value \\
\hline Mammals & 45 & 0.948 & $<0.0001$ & 0.20 & -0.11 & -2.84 & $\mathbf{0 . 0 0 7}$ \\
Rodentia & 24 & 0.826 & 0.0003 & 0.029 & -0.08 & -1.84 & $\mathbf{0 . 0 8}$ \\
Non-Rodentia & 21 & 0.934 & 0.0006 & 0.40 & -0.15 & -1.94 & $\mathbf{0 . 0 7}$ \\
\hline
\end{tabular}

Supplementary Table 12: Results of a compositional data analysis between brain size, adipose depots mass and fat-free body mass. Pair-wise phylogenetic least-squares regression (PGLS) between the transformed variables. a) $\mathrm{N}=100$ species, b) $\mathrm{N}=45$ species.

\begin{tabular}{|c|c|cccccc|}
\cline { 3 - 8 } \multicolumn{2}{c|}{} & \multicolumn{7}{c|}{ PGLS } \\
\hline Group & $\mathrm{N}$ & $\lambda$ & $\mathrm{P}(\lambda=0)$ & $\mathrm{P}(\lambda=1)$ & $\beta$ & t-value & $\mathrm{p}$-value \\
\hline Mammals & 100 & 0.000 & 1.00 & $<0.0001$ & -0.64 & -8.21 & $<\mathbf{0 . 0 0 0 1}$ \\
Primates & 23 & 0.766 & 0.033 & 0.021 & -0.57 & -5.78 & $<\mathbf{0 . 0 0 0 1}$ \\
Carnivora & 28 & 0.000 & 1.00 & 0.0008 & -0.66 & -4.96 & $<\mathbf{0 . 0 0 0 1}$ \\
Rodentia & 29 & 1.000 & $<0.0001$ & 1.00 & -0.80 & -9.19 & $<\mathbf{0 . 0 0 0 1}$ \\
\hline
\end{tabular}

\begin{tabular}{|c|c|c|c|c|c|c|c|c|c|c|}
\hline \multicolumn{2}{|l|}{ b) } & \multicolumn{6}{|c|}{ PGLS } & \multicolumn{3}{|c|}{ Raw data $(\lambda=0)$} \\
\hline Group & $\mathrm{N}$ & $\lambda$ & $\mathrm{P}(\lambda=0)$ & $\mathrm{P}(\lambda=1)$ & $\beta$ & t-value & $\mathrm{p}$-value & $\beta$ & t-value & p-value \\
\hline Mammals & 45 & 0.000 & 1.00 & $<0.0001$ & -0.80 & -6.78 & $<0.0001$ & & & \\
\hline Rodentia & 24 & 1.000 & 0.21 & 1.00 & -0.80 & -9.00 & $<0.0001$ & -0.73 & -4.82 & $<0.0001$ \\
\hline Non-Rodentia & 21 & 0.000 & 1.00 & 0.0001 & -0.79 & -4.06 & $<0.0001$ & & & \\
\hline
\end{tabular}




\subsection{The special case of primates}

This section contains additional results on the relationship between brain size and adipose depots mass in primates, taking data quality into account.

Our hypothesis predicted that the negative correlation between brain size and adipose depots mass should also be present in primates as a group, but it was not (cf. Suppl. Table 4a). Even if the whole primate order would be following a cognitive buffering strategy in comparison to other mammalian taxa, we still expect that the relationship would be valid within the group, as not all primate species equally rely on cognitive buffering ${ }^{15}$. There are four reasons leading us to conclude that our data of primates do not accurately reflect the trade-off between adipose depots and brain size.

First, as our primate specimens were captives from a variety of husbandry conditions, there may be a large variation in fat storage in our sample which does not reflect "true" biological variation. Seasonality should be less of a concern for captive primates, but age and cause of death may strongly affect adipose depots in unpredictable directions. Indeed, many closely related species in our sample differ considerably in their amount of adipose depots. As tip contrasts have a large impact on the results of phylogenetic methods, they may mask an underlying trend $\left(\mathrm{cf}^{55}\right)$.

Second, Pond ${ }^{13}$ reported that subcutaneous fat stores are more conspicuous in primates than in other groups, and we know from qualitative comparisons that different primate species store adipose depots at different places in their body. The small-brained fat-tailed dwarf lemurs (Cheirogaleus medius and C. major) store fat in their tails, increasing their body mass up to $78 \%$ before hibernation $^{56}$. Orangutan males exhibit fatty cheek pads, and probably also store fat around the neck, in addition to abdominal fat stores ${ }^{57}$. Even within humans, males differ in fat store distribution from females ${ }^{22}$. Therefore, our measurements and subsequent scaling of abdominal fat stores may not be accurately estimating total body fat in some primate species, and the resulting error may mask any underlying correlation.

Third, peculiarities of the gastrointestinal tract of foregut fermenters may exert an influence on the capacity to store fat in captive animals. In the order of primates, only the subfamily Colobinae belongs to this group. In contrast to hindgut fermenters (i.e. all other primates), a diet of energy-dense, low-fiber foods does not increase body mass in this group, but rather leads to a loss of body mass, diarrhea, and premature death ${ }^{58}$. This is a well-known phenomenon in captive colobines, which are extremely sensitive to husbandry conditions and are 
relatively rarely kept in zoos. Our sample contains two colobine species (Colobus polykomos and Trachypithecus vetulus). If these are excluded from the analysis, a very weak negative trend between brain size and adipose depots mass appears in the reduced sample $(\mathrm{N}=21$, lambda $=0.692$, p-value of adipose depots on brain size controlling for body mass: 0.368 , beta $=-0.072$ ).

Fourth, some of the primate specimens in our sample were rather light-weight in comparison to the wild adult body mass of the respective sex $(<75 \%$, Cebus apella, Macaca nigra, Symphalangus syndactylus, Theropithecus gelada, and Mandrillus sphinx). If we exclude these specimens from the analysis (in addition to the two colobines, see point 3 ), the negative trend between adipose depots and brain size, controlling for body mass, actually becomes significant $(\mathrm{N}=16$, lambda $=0.018, \mathrm{p}=0.022$, beta $=-0.180$ ). The same result is obtained by excluding only one single data point, Cebus apella $(\mathrm{N}=20$, lambda $=0$, $\mathrm{p}$-value of adipose depots on brain size controlling for body mass: 0.022 , beta $=-0.181$ ). The latter species is represented by a single female individual of only $70 \%$ of the normal female body mass of this species. However, its adipose depots mass is, contrary to the overall low body mass, very high in comparison to other primates (51.4g abdominal fat mass, $1750 \mathrm{~g}$ body mass). This leads to an extremely large contrast with its closest relative in our sample, a male Saimiri boliviensis, which exhibits a very low value of adipose depots mass (4.85g abdominal fat mass, 1003g body mass). But how can we know which of the two individuals is an outlier? For Saimiri, we have dissected two other specimens of a closely related species, Saimiri sciureus, which were not included in the final sample because their skull was damaged. All three Saimiri individuals exhibit a similarly low amount of abdominal adipose depots relative to body mass (less than $1 \%$ abdominal fat in all three specimens, as compared to $3 \%$ in the Cebus apella). It is therefore likely that the Cebus apella data point is an outlier, but we cannot say whether this is also found in other individuals of the species or genus or whether it is an abnormality of this specimen.

In conclusion, all four points taken together confirm that there is good reason to maintain that the negative correlation between adipose depots and brain size would also be found in primates, if more and more accurate data could be obtained. Obviously, we need more and more accurate data to settle this issue. 


\subsection{Costs of transporting adipose depots}

This section contains a discussion of the energetic cost of transporting adipose depots in mammals, and a calculation of these costs in humans vs. chimpanzees.

Interspecifically, the metabolic cost of transport in animals increases with body mass, as demonstrated by Taylor et al. ${ }^{59}$ for a wide range of animals. The cost of transport per gram body mass decreases with body mass ${ }^{-0.33}$, and thus the cost of transport of the whole body increases with body mass ${ }^{0.66}$. However, the relationship varies between orders or taxa groups, and there seems to be a steeper increase in rodents $(\mathrm{N}=15$ species $)$ and primates $(\mathrm{N}=10$, including Tupaia and Homo sapiens) than in artiodactyls $(\mathrm{N}=10)$, carnivores $(\mathrm{N}=11)$ or marsupials $(\mathrm{N}=11)^{59}$. In any case, this interspecific relationship is likely to yield an underestimate of the metabolic cost of transport of additional adipose depots, as the musculoskeletal system does not grow in concert with additional body mass from fat storage.

Overall, the energy spent on locomotion varies widely between individuals of a species, depending on season, reproductive state, food availability and other variables. It can be estimated from day ranges and time spent on locomotion ( $\mathrm{cf}^{16,60}$ ), although day range is usually underestimating actual path length, which has a fractal dimension, and time spent on locomotion is confounded by the fact that some locomotion is also needed for other activities such as foraging or social life. Small animals of less than 500g body mass spend only about $1 \%$ of their total energy on locomotion, whereas this value increases to $5-15 \%$ in larger animals ${ }^{16}$.

These values may seem to be rather small. However, the actual cost of carrying adipose depots may not only consist of an increase of the direct costs of locomotion, but in addition of an indirect cost of being less swift to escape predators. This cost depends on the lifestyle and may be higher in terrestrial and/or small species. Jumping distance is impaired in fatter cats ${ }^{61}$, and in small monkeys forced to carry additional weights on their trunk ${ }^{62}$. Maximum running speed does not generally increase with body mass within taxa ${ }^{63}$, and it even decreases in artiodactyls. In human athletes, the fastest and most enduring sportsmen are usually those with the lowest percentage of body fat, if training levels are also taken into account ${ }^{64}$. Therefore, it seems justified to assume that an increased percentage of adipose depots, without a parallel increase in the size of the musculoskeletal system, significantly decreases maximum running speeds also in animals. 
Extant human foragers spend between $22 \%$ and $18 \%$ of their daily energy expenditure on locomotion (estimates of Leonard and Robertson ${ }^{60}$, and of Isler and van Schaik ${ }^{7}$ following a model of Pontzer and Wrangham ${ }^{65}$ ), and chimpanzees between $16 \%$ and $30 \%$ (same sources). Using the same equations, $10 \%$ additional fat stores would increase the percentage of energy used for locomotion about $1 \%$ in humans, but $2-3 \%$ in chimpanzees (the exact chimpanzee value differs according to whether we use the Taylor and Rowntree ${ }^{66}$ equation for treadmill running of a juvenile chimpanzee (body mass $17 \mathrm{~kg}$ ), or the Taylor et al. ${ }^{59}$ equation derived from 10 primate species).

Recently, Hanna and colleagues ${ }^{67}$ have shown that vertical climbing efficiency increases only very slightly with body mass in primates (exponent of 0.11 , not significantly different from zero), i.e. the cost of travel during climbing is almost directly proportional to body mass. We therefore expect that animals that include a fair amount of vertical travel are affected more strongly than predominantly terrestrial species by an increase in the size of adipose depots.

In conclusion, direct and indirect costs of adipose depots through their effect on locomotor efficiency are clearly evident, although they probably vary quite considerably between lineages or even more closely related species. Furthermore, available data and models confirm that the costs of quadrupedal locomotion and vertical climbing in nonhuman apes show a steeper increase with body mass than human walking or running. Efficient bipedalism similar to that of modern humans probably evolved in the first members of the genus Homo about $2 \mathrm{Ma} \mathrm{ago}^{27}$. Therefore, we conclude that storing fat would be less costly for an efficient biped such as early Homo than for their ancestors. 


\section{Supplementary references}

36 Chivers, D. J. \& Hladik, C. M. Morphology of the gastrointestinal tract in primates: comparisons with other mammals in relation to diet. J. Morphol. 166, 337-386 (1980).

37 Harvey, P. H. \& Cluttonbrock, T. H. Life-history variation in primates. Evolution 39, 559581 (1985).

38 Arnold, C., Matthews, L. J. \& Nunn, C. L. The 10kTrees website: a new online resource for primate phylogeny. Evol. Anthropol. 19, 114-118 (2010).

39 Plavcan, J. M. Sexual dimorphism in primate evolution. Yearb. Phys. Anthropol. 116, 2553 (2001).

40 Aschoff, J., Günther, B. \& Kramer, K. Energiehaushalt und Temperaturregulation, (Urban and Schwarzenberg, Munich, 1971).

41 Bininda-Emonds, O. R. P. et al. The delayed rise of present-day mammals. Nature 446, 507-512 (2007).

42 Volleth, M. \& Heller, K. G. Phylogenetic relationships of vespertilionid genera (Mammalia, Chiroptera) as revealed by karyological analysis. Z. Zool. Syst. Evol. 32, 1134 (1994).

43 Koepfli, K.-P. et al. Multigene phylogeny of the Mustelidae: resolving relationships, tempo and biogeographic history of a mammalian adaptive radiation. BMC Biol. 6, 10 (2008).

44 Robovský, J., ŘIčánková, V. \& Zrzavý, J. Phylogeny of Arvicolinae (Mammalia, Cricetidae): utility of morphological and molecular data sets in a recently radiating clade. Zool. Scr. 37, 571-590 (2008).

45 Lecompte, E. et al. Phylogeny and biogeography of African Murinae based on mitochondrial and nuclear gene sequences, with a new tribal classification of the subfamily. BMC Evol. Biol. 8, 199 (2008).

46 Michaux, J., Reyes, A. \& Catzeflies, F. Evolutionary history of the most speciose mammals: molecular phylogeny of muroid rodents. Mol. Biol. Evol. 18, 2017-2031 (2001).

47 Rowe, D. L. \& Honeycutt, R. L. Phylogenetic relationships, ecological correlates, and molecular evolution within the Cavioidea (Mammalia, Rodentia). Mol. Biol. Evol. 19, 263-277 (2002). 
48 Veniaminova, N. A., Vassetzky, N. S., Lavrenchenko, L. A., Popov, S. V. \& Kramerov, D. A. Phylogeny of the order Rodentia inferred from structural analysis of short retroposon B1. Russ. J. Genet. 43, 757-768 (2007).

49 Wilson, D. E. \& Reeder, D. M. Mammal Species of the World. A Taxonomic and Geographic Reference 3rd edn (Johns Hopkins University Press, 2005).

50 Christians, J. K. Controlling for body mass effects: Is part-whole correlation important? Physiol. Biochem. Zool. 72, 250-253 (1999).

51 Aitchinson, J. The statistical analysis of compositional data (with discussion). J. Roy. Stat. Soc. B 44, 139-177 (1982).

52 Muldowney, D., Connolly, J. \& Keane, M. G. Compositional data analysis in the study of carcass composition of beef cattle. Livest. Prod. Sci. 67, 241-251 (2001).

53 Egozcue, J. J., Pawlowsky-Glahn, V., Mateu-Figueraz, G. \& Bercelo-Vidal, C. Isometric logratio transformations for compositional data analysis. Math. Geosci. 35, 279-300 (2003).

54 van den Boogaart, K. G. \& Tolosano-Delgado, R. "Compositions": a unified R package to analyze compositional data. Comput. Geosci. 34, 320-338 (2008).

55 Martin, R. D., Genoud, M. \& Hemelrijk, C. Problems of allometric scaling analysis: examples from mammalian reproductive biology. J. Exp. Biol. 208, 1731-1747 (2005).

56 Müller, A. E. Aspects of social life in the fat-tailed dwarf lemur (Cheirogaleus medius): inferences from body weights and trapping data. Am. J. Primatol. 49, 265-280 (1999).

57 Winkler, L. A. Morphology and relationships of the orangutan fatty cheek pads. Am. J. Primatol. 17, 305-319 (1989).

58 Nijboer, J. Fibre intake and faeces quality in leaf-eating primates, $\mathrm{PhD}$ dissertation, University of Utrecht (2006).

59 Taylor, C. R., Heglund, N. C. \& Maloiy, G. M. O. Energetics and mechanics of terrestrial locomotion. I. Metabolic energy-consumption as a function of speed and body size in birds and mammals. J. Exp. Biol. 97, 1-21 (1982).

60 Leonard, W. R. \& Robertson, M. L. Comparative primate energetics and hominid evolution. Am. J. Phys. Anthropol. 102, 265-281 (1997).

61 Harris, M. A. \& Steudel, K. The relationship between maximum jumping performance and hind limb morphology/physiology in domestic cats (Felis silvestris catus). J. Exp. Biol. 205, 3877-3889 (2002). 
62 Garber, P. A., Blomquist, G. E. \& Anzenberger, G. Kinematic analysis of trunk-to-trunk leaping in Callimico goeldii. Int. J. Primatol. 26, 223-240 (2005).

63 Garland, T. The relation between maximal running speed and body mass in terrestrial mammals. J. Zool. 199, 157-170 (1983).

64 Knechtle, B. et al. Predictor variables of performance in recreational male long-distance inline skaters. J. Sport. Sci. 29, 959-966 (2011).

65 Pontzer, H. \& Wrangham, R. W. Climbing and the daily energy cost of locomotion in wild chimpanzees: implications for hominoid locomotor evolution. J. Hum. Evol 46, $317-$ 335 (2004).

66 Taylor, C. R. \& Rowntree, V. J. Running on two or on four legs: Which consumes more energy? Science 179, 186-187 (1973).

67 Hanna, J. B., Schmitt, D. \& Griffin, T. M. The energetic cost of climbing in primates. Science 320, 898 (2008). 


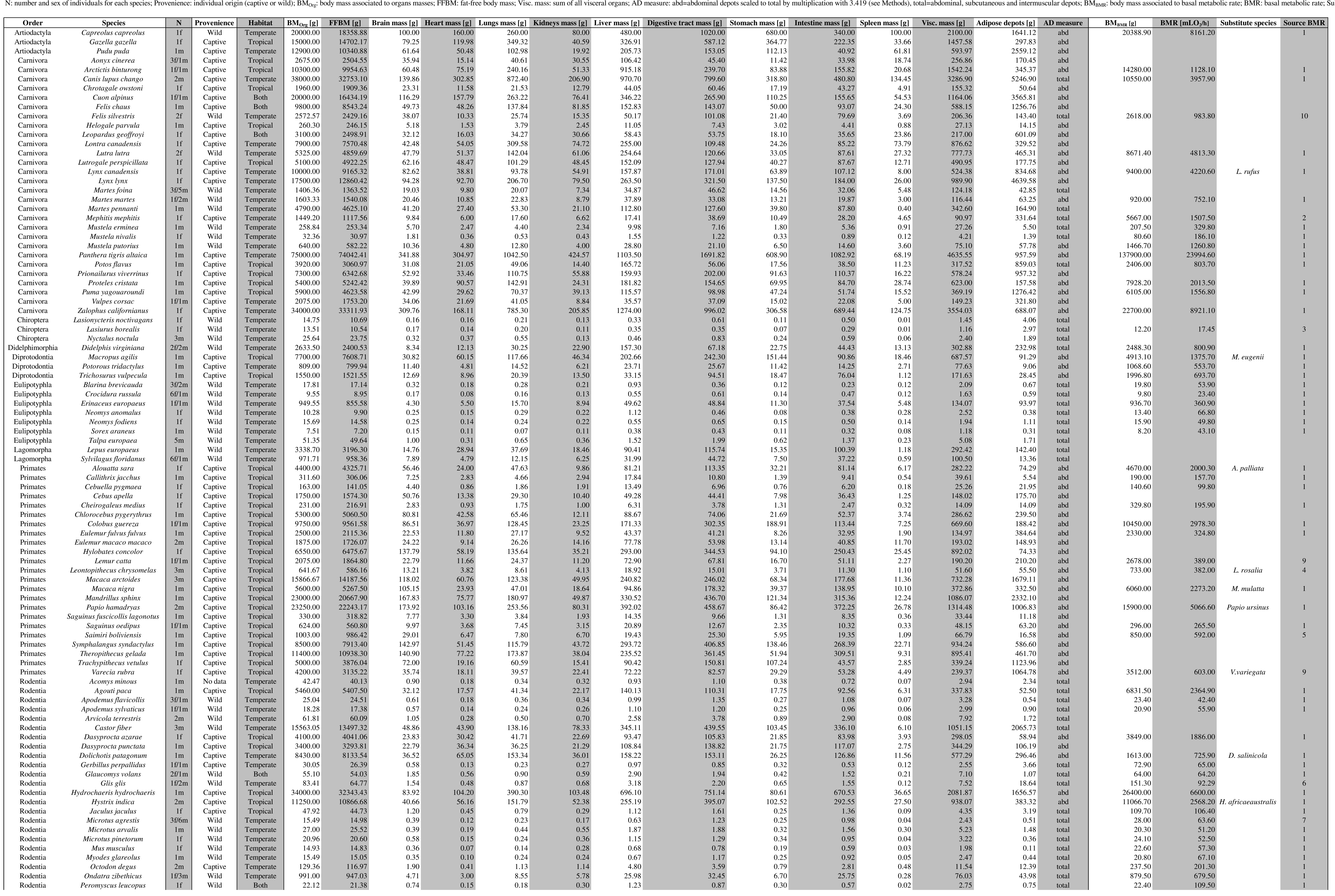




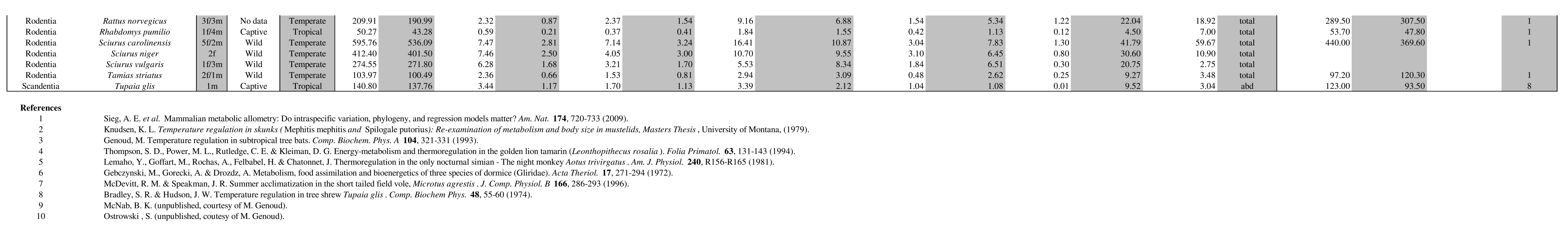


